\title{
Turbulent, stratified flow through a suspended shellfish canopy: implications for mussel farm design
}

\author{
Craig L. Stevens ${ }^{1, *}$, Jens Kjerulf Petersen ${ }^{2}$ \\ ${ }^{1}$ National Institute for Water and Atmospheric Research, Greta Point, 6022 Wellington, New Zealand \\ ${ }^{2}$ Dansk Skaldyrcenter, Øroddevej 80, 7900 Nykøbing Mors, Denmark
}

\begin{abstract}
Observations were used to quantify the influences of turbulent flow and mixing through the suspended canopy formed by a shellfish aquaculture farm in the microtidal Danish Limfjorden. Observations included current meter/profiler timeseries data and turbulence microstructure profiling. The influence was 2 -way in that the turbulence is partially driven by the canopy and in turn the canopy is affected by the turbulence. The canopy reduced the flow speeds within its interior, which was sufficient to reduce levels of turbulent kinetic energy so that withincanopy rates of turbulent kinetic energy dissipation $\varepsilon$ were between $10^{-8}$ and $5 \times 10^{-6} \mathrm{~m}^{2} \mathrm{~s}^{-3}$. Stratification and turbulence were generally inter-related. It was difficult to link the canopy effect to changes in stratification. This was partly due to a high degree of natural variability and partly because the canopy did not appear to generate that much mixing relative to background variability. Vertical diffusivities enabled estimates of the effect of mixing on nutrient depletion and suggest that in the investigated farm set-up vertical diffusivities are secondary in terms of contribution to this relationship but that they could play a dominant role in farms with a more spacious or compressed set-up of canopies. However, vertical flux estimates imply that there must be transverse fluxes of material. Results suggest several avenues for enhanced sustainable shellfish production. For example, canopy flushing can be enhanced with suitable arrangement of crop within a farmed area (heterogeneity). In addition, stratification persists within the canopy and so exposure to nutrient-deplete water can be minimized through staggered crop heights. However, to benefit from this knowledge, improved understanding of long-term variability in the background environment is required.
\end{abstract}

KEY WORDS: Marine canopy $\cdot$ Heterogeneity $\cdot$ Shellfish $\cdot$ Mixing $\cdot$ Stratification $\cdot$ Aquaculture Resale or republication not permitted without written consent of the publisher

\section{INTRODUCTION}

Shellfish aquaculture is one of the lower-impact methods of generating high protein food (e.g. Ackman 1989). In order to facilitate the sustainable expansion of production, whilst simultaneously minimizing impact, it is important to develop reliable predictive models of biophysical processes in and around shellfish aquaculture canopies. Uptake of seston by the shellfish and expulsion of waste are intimately entwined with the flow and circulation in and around the canopy. Initial perspectives on this assumed a homogeneous canopy and an unstratified water column (e.g. Pilditch et al. 2001, Plew et al. 2005). However, transport processes are influenced by turbulent mixing, stratification (Plew et al. 2006, Stevens et al. 2008) and canopy structure (e.g. Jamali et al. 2008, Delaux et al. 2011) and so analyses must extend beyond the assumptions that the canopy is hydrodynamically invisible or that the water column is homogenous. This exploratory study considers the influence of stratification and turbulent mixing on the overall productivity of a shellfish canopy. The present study focuses on the farm-driven changes to tur- 
bulence and stratification as well as the influence of existing and modified turbulence on the farm itself.

Aquaculture structures, especially shellfish farms, create a highly ordered canopy comprising a number of different physical length scales (Fig. 1). Typically, the structures are built up of 'longlines' - a line connecting a group of floats and weights that are align-
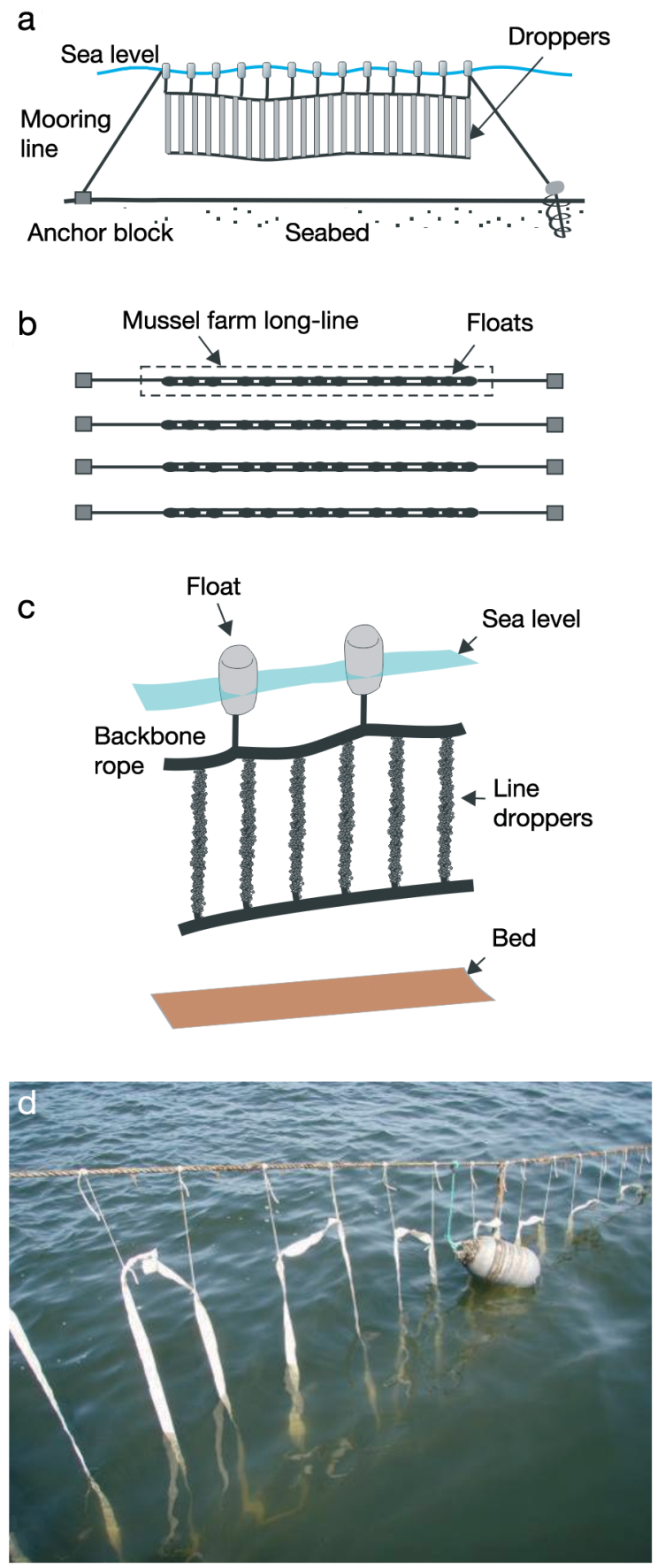

Fig. 1. Longline arrangement showing (a) elevation view, (b) plan view and (c) close-up of dropper arrangement. (d) A section of new unstocked line being lifted from the water ed horizontally over a distance of the order of $100 \mathrm{~m}$. Perhaps 12 or so longlines are grouped in parallel, forming a 'block'. A 'farm' may comprise anywhere from 1 to 10 blocks and sometimes more. Juvenile shellfish are typically seeded on rope (the 'crop') that is then hung vertically from this longline, the mass of which increases as the shellfish grow (e.g. Stevens et al. 2008).

Understanding of marine flow interactions in and around such canopies is indebted to the extensive terrestrial-atmospheric canopy literature that is wellreviewed elsewhere (e.g. Finnigan 2000). Considering the marine environment, flow-canopy interactions of relevance to shellfish canopies include flow distortion (Gaylord et al. 2007), edge effects (e.g. Ghisalberti 2009), patchiness (Song et al. 1997, Folkard 2011), tidal modulation of canopy density (Stevens et al. 2003), within-canopy transport (Jackson \& Winant 1983, Rosman et al. 2007) and interaction with stratification (Jackson 1984, Plew et al. 2006, Jamali et al. 2008). Much of this knowledge can be directly utilized in order to improve shellfish aquaculture production.

A key aspect that emerges from these studies, either through their conclusions or what they choose to avoid, is the fundamental importance of the interaction between turbulence and stratification. The coastal ocean is almost always turbulent in some parts and stratified in others to a varying degree and these competing factors have a profound and controlling influence on ecosystems. Much work has gone into determining the impact of the generation of stratification and its destruction by turbulence in estuaries (Baumert et al. 2005, Chanson \& Trevethan 2010). The focus of the present study is to consider the scales of turbulence in the context of the introduction of a shellfish canopy structure. The structure acts as an energy converter as it both absorbs energy (slows down flow) and generates turbulence (i.e. multiple wakes).

A potentially important aspect in the generation of turbulence and its dissipation is the effect of canopy heterogeneity. This is often termed patchiness when describing natural canopies (e.g. Song et al. 1997, Bohrer et al. 2008) that have gaps (Folkard 2011). However, a difference between natural canopies and shellfish structures is the highly ordered nature of the shellfish canopy. Heterogeneity here refers to the farm layout and structure such as the spacing of longlines, the depth, diameter and spacing of the crop ropes, the size of the canopy blocks (i.e. number and length of longlines) and the number of blocks. Farms have regional differences in the kind and degree of 
heterogeneity associated with how the local industries have evolved (Stevens et al. 2008). Although we focus on longline structures in this paper (based on Danish and, to a lesser extent, New Zealand farming practice), some industries (e.g. Spain) use raft arrangements that are vastly different at the canopy (raft/longline) scale but less different at either the macro- (farm) or micro- (crop rope) scale.

The objective of the present study is to understand how turbulent stratified flow interacts with a suspended shellfish canopy with a view to suggesting ways of arranging farms that might lessen their environmental impact and at the same time maximize their production. Using a combination of mechanistic scaling and field observation, we address several questions: (1) is the flow and stratification distorted by the canopy; (2) is there some signature in this distortion relating to canopy heterogeneity; (3) can estimates be made of in-canopy diffusivities; and (4) what are the implications of stratification and mixing for food availability within the canopy? These questions are considered in the 'Discussion' from the perspective of 3 scales: large farm/ canopy scale, intermediate dropper scale and small, i.e. individual mussel, scale. Ultimately, these questions then feed an applied question: (5) can these improvements in understanding suggest changes to farm structure and/or practice that result in better crop/ impact ratios?

\section{MATERIALS AND METHODS}

Canopy, flow, stratification and turbulence measurements were resolved from a group of mussel farms in the Limfjorden in Jutland, Denmark $\left(56^{\circ} 41.2^{\prime} \mathrm{N}, 09^{\circ} 08.1^{\prime} \mathrm{E}\right.$; Fig. 2), during spring 2007. The farms were located in shallow water between 6 and $9 \mathrm{~m}$ deep (Fig. 2c) in a region of the microtidal Skive Fjord close by the flow constriction at Sundsøre-Halpvsund. The
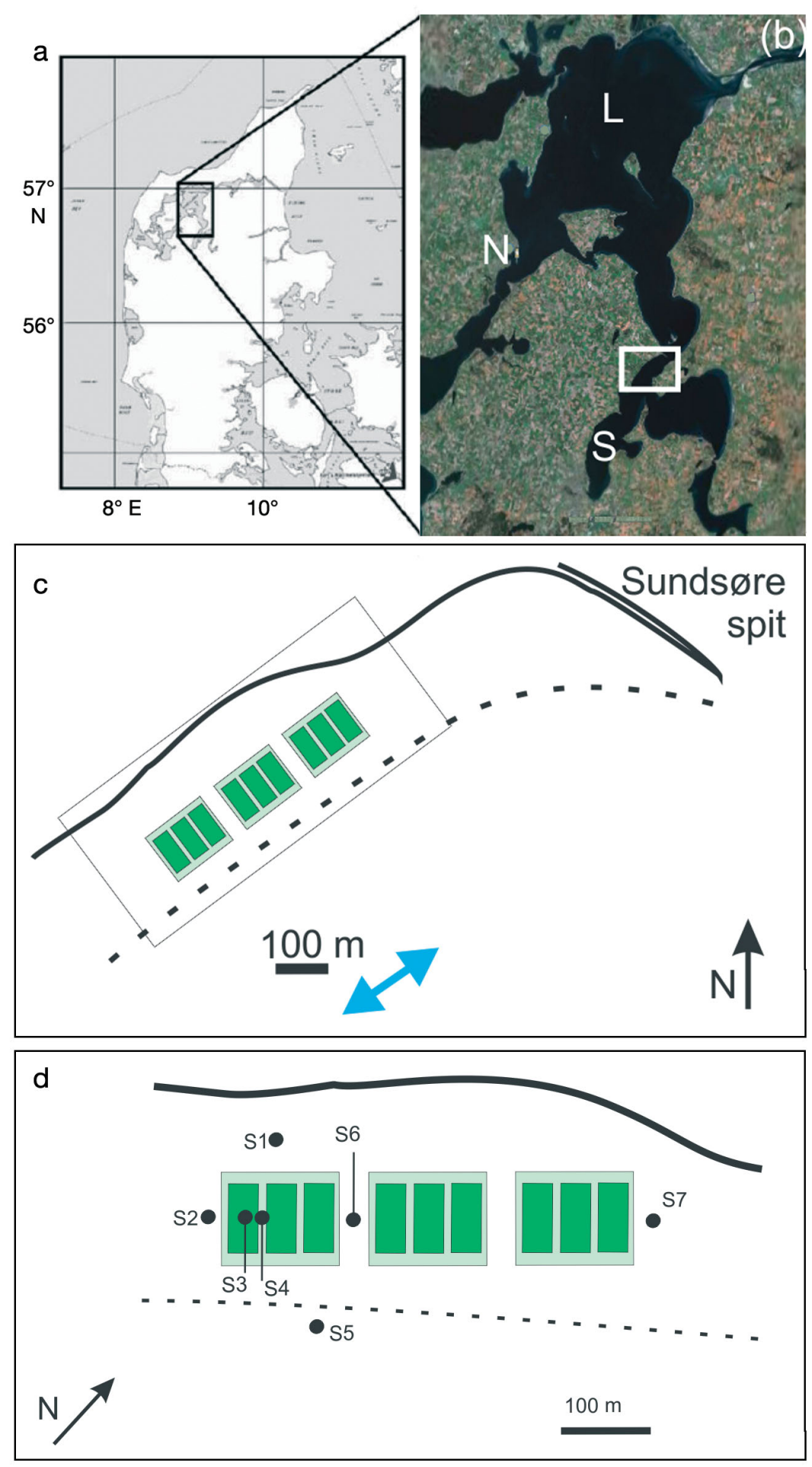

Fig. 2. Location of field site showing (a) the location of Limfjorden in Denmark, and (b) the field area within the eastern Limfjorden (L) near the township of Nykøbing (N) and north of Skive Fjord (S). (c,d) The farm units (light green boxes) are located to the southwest of the Sundsøre spit. The farm blocks (dark green boxes) and sampling stations (in d: S1 to S7) are marked along with the $7 \mathrm{~m}$ depth contour (dashed line). Thick black lines represent the coast line. The background tidal flow alignment (blue arrow) is also shown (in c). The sampling stations focused on the southern end of the farms (d) 
Table 1. Station locations

\begin{tabular}{|lccc|}
\hline Station & Depth $(\mathrm{m})$ & Location (latitude, longitude) & Notes \\
\hline 1 & 3.5 & $56^{\circ} 41.026^{\prime} \mathrm{N}, 09^{\circ} 08.138^{\prime} \mathrm{E}$ & Inshore of farms \\
2 & 5.8 & $56^{\circ} 41.044^{\prime} \mathrm{N}, 09^{\circ} 07.959^{\prime} \mathrm{E}$ & Southern extent of farms \\
3 & 6.5 & $56^{\circ} 41.198^{\prime} \mathrm{N}, 09^{\circ} 08.132^{\prime} \mathrm{E}$ & Center of study farm block \\
4 & 7.5 & $56^{\circ} 41.246^{\prime} \mathrm{N}, 09^{\circ} 08.192^{\prime} \mathrm{E}$ & Small gap between blocks \\
5 & 7.8 & $56^{\circ} 41.029^{\prime} \mathrm{N}, 09^{\circ} 08.431^{\prime} \mathrm{E}$ & $\begin{array}{c}\text { Outside of farm system } \\
6\end{array}$ \\
7.5 & $56^{\circ} 41.572^{\prime} \mathrm{N}, 09^{\circ} 08.867^{\prime} \mathrm{E}$ & $\begin{array}{c}\text { Big gap between blocks } \\
\text { North extent of farms }\end{array}$ \\
\hline
\end{tabular}

region contained 3 farm units, separated by $150 \mathrm{~m}$ gaps. Each unit contained 3 blocks (or sections) separated by a $30 \mathrm{~m}$ gap and each block in turn consisted of 32 longlines that were $200 \mathrm{~m}$ long. The mussel crop canopy was suspended in short strap lines between depths of 3 and $5 \mathrm{~m}$ with the fully cropped straps $\sim 15 \mathrm{~cm}$ in diameter. Sampling stations (Table 1, Fig. 2d) were located inshore of the farms (Stn 1), at the south end of the farms (Stn 2), within a section (Stn 3), in the small gap between sections (Stn 4), offshore of the farms (Stn 5), in the big gap inbetween units (Stn 6) and, finally, to the north of all the units (Stn 7).

Meteorology was recorded at the Danish Shellfish Centre in Nykøbing (Fig. 2b). Current profiles were recorded with a Nortek AquaDopp $1000 \mathrm{kHz}$ acoustic Doppler current profiler (ADCP) and an Aanderaa $600 \mathrm{kHz}$ recording Doppler current profiler (RDCP). These devices were bottom-mounted simply by pushing the cases into the mud. They were located for several days at a time at Stns 2 and 3 and then swapped. Notably, systematic low-amplitude variation in vertical velocity was observed. As the housing was fixed in space, this cannot be a physical crosstalk effect whereby horizontal velocity modulated the vertical component.

A taut mooring located outside the farm area (Stn 5) supported thermistors (SeaMon; sampling at 1 min intervals, nominal 7.4, 3.5 and $1.4 \mathrm{~m}$ depths) and 2 current meters (Aanderaa recording current meter, RCM, 9; sampling at 5 min intervals, nominal depths of 5.3 and $2.1 \mathrm{~m}$ ). Velocity turbulence measurements were recorded with a Nortek Vector acoustic velocimeter (sampling velocities at a point at $8 \mathrm{~Hz}$ in 4096 point bursts every $20 \mathrm{~min}$ ) and mounted on this taut mooring for $\sim 3 \mathrm{~d}$ periods each at Stns 3 and 4 .

High-resolution profiles of stratification and temperature-gradient derived turbulence properties were gathered using a PME SCAMP temperature gradient microstructure profiler. This records temperature and temperature gradient at a resolution of $\sim 2 \mathrm{~mm}$ and conductivity at a resolution of $\sim 10 \mathrm{~mm}$. A total of 146 profiles were collected during 7 'transects' that recorded triplets of profiles at each station. The triple profiles were recorded in quick succession in order to gain some perspective on the variability. These data enable independent estimation of turbulent kinetic energy dissipation rate (ع) (e.g. Ruddick et al. 2000) and the vertical diffusivity $\left(K_{\mathrm{v}}\right)$ of material. The SCAMP also had a micro-fluorometer, which provided complementary readings to a handdeployed Turner Designs SCUFA fluorometer with a resolution of $\sim 10 \mathrm{~cm}$.

\section{Scaling and mechanics}

A number of key parameters assist in the description of flow around the canopy (parameters summarized in Table 2). When layers in a stratified fluid flow differently to one another, the result is velocity 'shear' $\left(U_{\mathrm{zi}} \mathrm{s}^{-1}\right)$. Perturbations will exist in this flow that will grow if this shear is of sufficient strength relative to the local stratification. The primary measure of strength of stratification is the buoyancy frequency squared $N^{2}=\left(g / \rho_{0}\right) \rho_{z}$, where $g$ is gravitational acceleration, $\rho_{0}$ is a reference density (here $1020 \mathrm{~kg} \mathrm{~m}^{-3}$ ) and the $z$ subscript is the partial vertical derivative with respect to depth. Oceanic values of $N^{2}$ are typically small (perhaps $\sim 10^{-4} \mathrm{~s}^{-2}$ ) compared with values seen in estuaries, which can reach nearly unity.

Thus, from the perspective of mixing, the stability of shear-driven flows is a balance of buoyancy and velocity shear $\left(U_{z}\right)$ parameterized using the gradient Richardson number $\mathrm{Ri}_{\mathrm{gr}}$, described by:

$$
\mathrm{Ri}_{\mathrm{gr}}=\frac{N^{2}}{U_{z}^{2}}
$$

where the shear is $U_{z}^{2}=\left(u_{z}\right)^{2}+\left(v_{z}\right)^{2}$, where $u_{z}$ and $v_{z}$ are the vertical gradients of the cartesian components of velocity. Strictly, $\mathrm{Ri}_{\mathrm{gr}}<0.25$ (Turner 1973) is the condition for the onset of instability. Gauging the influence of the canopy and its structural heterogeneity on this parameter is key to understanding the turbulence and resulting mixing caused by canopyinduced shear. Plew et al. (2006) examined baroclinic (i.e. tilted isopycnals - lines of constant density) depression of local water density structure by a canopy and used a Froude number argument to parameterize the likely depression of the pycnocline (density interface). Thus these authors described the interface deflection $\Delta z$ as: 
Table 2. Parameters, descriptions, formulae and units used in the present study

\begin{tabular}{|c|c|c|}
\hline Parameter & Formulation & Units \\
\hline \multicolumn{3}{|l|}{ Fundamental } \\
\hline Buoyancy frequency squared & $\begin{array}{l}N^{2}=\left(g / \rho_{0}\right) \rho_{z} \\
\bullet z \text { is the partial vertical derivative }\end{array}$ & $\mathrm{s}^{-2}$ \\
\hline Velocity shear squared & $U_{z}^{2}=\left(u_{z}\right)^{2}+\left(V_{z}\right)^{2}$ & $\mathrm{~s}^{-2}$ \\
\hline Rate of energy dissipation & $\varepsilon$ & $\mathrm{m}^{2} \mathrm{~s}^{-3}$ or $\mathrm{W} \mathrm{kg}{ }^{-1}$ \\
\hline \multirow{2}{*}{$\begin{array}{l}\text { Canopy scale } \\
\text { Non-dimensional isopycnal deflection }\end{array}$} & $\Delta z \quad U_{0}\left(1-\alpha^{2}\right)^{1 / 2}$ & \\
\hline & $\begin{array}{l}H_{\mathrm{c}} \\
-H_{\mathrm{c}} \text { is the canopy height } \\
\text { - } U_{0} \text { is the background flow speed } \\
\text { - } \alpha \text { is the canopy porosity factor }\end{array}$ & - \\
\hline Gradient Richardson number & $\mathrm{Ri}_{\mathrm{gr}}=\frac{N^{2}}{U_{z}^{2}}$ & - \\
\hline \multirow[t]{2}{*}{ Canopy slow-down } & $\frac{U(x)}{U_{0}}=\exp \left(-\frac{n_{\mathrm{A}} C_{\mathrm{d}} \varphi x}{2}\right)$ & - \\
\hline & $\begin{array}{l}-x \text { is the distance through canopy } \\
-n_{\mathrm{A}} \text { is the number of crop droppers } \\
-\phi \text { is the diameter of the crop line } \\
-C_{\mathrm{d}} \text { is the drag coefficient }\end{array}$ & \\
\hline \multicolumn{3}{|l|}{ Turbulence } \\
\hline Vertical diffusivity & $\begin{array}{l}K_{\mathrm{v}}=\Gamma\left(\varepsilon / N^{2}\right) \\
-\Gamma \text { is a coefficient, nominally } 0.2\end{array}$ & $\mathrm{~m}^{2} \mathrm{~s}^{-1}$ \\
\hline Kolmogorov length scale & $\begin{array}{l}L_{\mathrm{K}}=\left(\mathrm{v}^{3} / \varepsilon\right)^{1 / 4} \\
\bullet v \text { is kinematic viscosity }\left(\sim 10^{-6}\right)\end{array}$ & $\mathrm{m}$ \\
\hline Ozmidov length scale & $L_{\mathrm{Oz}}=\left(\varepsilon / N^{3}\right)^{1 / 2}$ & $\mathrm{~m}$ \\
\hline Biophysical & $n_{\mathrm{s}} q L$ & \\
\hline Depletion parameter (quasi-Damkohler number) & $\begin{array}{l}F=\frac{\Pi_{\mathrm{s}} q L}{U_{0}} \\
\text { - } n_{\mathrm{s}} \text { is the number of shellfish } \\
\text { per unit volume } \\
\text { - } q \text { is their individual filtration rate } \\
\text { - } L \text { is the length of the canopy }\end{array}$ & - \\
\hline
\end{tabular}

$$
\frac{\Delta z}{H_{\mathrm{c}}}=\frac{U_{0}\left(1-\alpha^{2}\right)^{1 / 2}}{N H_{\mathrm{c}}}
$$

where $H_{\mathrm{c}}$ is canopy height, $\mathrm{N}$ is the buoyancy frequency and $\alpha$ is a canopy flow reduction factor associated with canopy bulk porosity ( $\alpha=0$ is no canopy, $\alpha=1$ is a solid obstacle).

A further important element is the degree of flow reduction. A number of authors have examined and tested a simple canopy drag argument (Jackson \& Winant 1983, Plew et al. 2005, Gaylord et al. 2007) that quantifies the relative decrease in current magnitude within the farm $U(x)$ relative to the flow speed outside the farm $\left(U_{0}\right)$ :

$$
\frac{U(x)}{U_{0}}=\exp \left(-\frac{n_{\mathrm{A}} C_{\mathrm{d}} \varphi x}{2}\right)
$$

where $n_{\mathrm{A}}$ is the number of droppers per unit area, $C_{\mathrm{d}}$ is a drag coefficient, $\varphi$ is the dropper diameter and $x$ is the distance to the farm. Delaux et al. (2011) suggest that a pressure-based approach is required to extend this to 2-dimensional situations and this is revisited in the 'Discussion'.
A key question is whether within the majority of the canopy the strength of the turbulent kinetic energy increases (due to the presence of structural disturbance) or decreases (due to the reduced flow). This strength is related to the stratification through the gradient Richardson number argument. Stratification will almost certainly influence the flow-canopy interaction (Plew et al. 2006).

The degree of turbulence controls transport rates in near-crop boundary layers. Turbulence here is quantified using the rate of dissipation of turbulent kinetic energy $(\varepsilon)$. This was derived from both the Vector velocimeter and the SCAMP profiler. Estimates of $\varepsilon$ were resolved from the Vector using the inertial dissipation method that fits a frequency $^{-5 / 3}$ line to the energy spectrum, as described in Plew et al. (2006) and references therein. However, wave or noise effects often confounded this approach (see 'Results'), so that only 50 reliable estimates of $\varepsilon$ were obtained from 318 data segments. 
The SCAMP profiling approach had more success in this application with its lower noise floor for $\varepsilon$ reaching down to $\sim 10^{-10} \mathrm{~W} \mathrm{~kg}^{-1}$ (or $\mathrm{m}^{2} \mathrm{~s}^{-3}$ ) which would be found in pelagic oceans or deep lakes. Estuarine flows with strong tides might reach up to $10^{-4} \mathrm{~W} \mathrm{~kg}^{-1}$. The dissipation rate is related to the vertical diffusivity of material, $K_{\mathrm{v}}$, which is directly resolvable from the temperature gradient data sampled with SCAMP (Ruddick et al. 2000). Thus, knowing background nutrient concentration gradients $\left(C_{z}\right)$ it is possible to estimate nutrient fluxes $(F)$ using Fickian diffusion, whereby $F=-K_{\mathrm{v}} C_{z}$. Furthermore, the bounds of turbulent eddy size can be quantified in terms of $\varepsilon$. The smallest variation in velocity occurs at the Kolmogorov length scale: $L_{\mathrm{K}}=\left(v^{3} / \varepsilon\right)^{1 / 4}$, where $v$ is the kinematic viscosity. The largest vertical scale before stratification influences the variability is given as the Ozmidov length scale: $L_{\mathrm{Oz}}=\left(\varepsilon / N^{3}\right)^{1 / 2}$.

From a biophysical perspective, the primary non-dimensional parameter for evaluating productivity of a shellfish farm is the ratio of the flux of nutrients into the farm relative to the amount being filtered. This type of parameter has been developed in the context of uptake by macroalgae (Kregting et al. 2008, Fram et al. 2008) and corals (Lowe et al. 2005) and so has aspects in common with the Damköhler number (Mcmurtry et al. 1989). At its simplest, the flow into the farm is given by $U_{0} W H_{\mathrm{c}}\left(\mathrm{m}^{3}\right.$ $\mathrm{s}^{-1}$ ), where $U_{0}$ is the flow speed outside the farm, $W$ is the farm width and $H_{\mathrm{c}}$ is crop depth, whereas the volume filtered per unit time (depleted) is given as $D=n_{\mathrm{s}} q W H_{\mathrm{c}} L$, where $n_{\mathrm{s}}$ is the number of shellfish per unit volume, $q$ is their individual filtration rate and $L$ is the length of the farm. Hence, a flushing ratio $F$ is given as:

$$
F=\frac{n_{s} q L}{U_{0}}
$$

but this does not take into account refiltration, vertical mixing or any aspects of actual nutrient concentration or efficiency of removal.
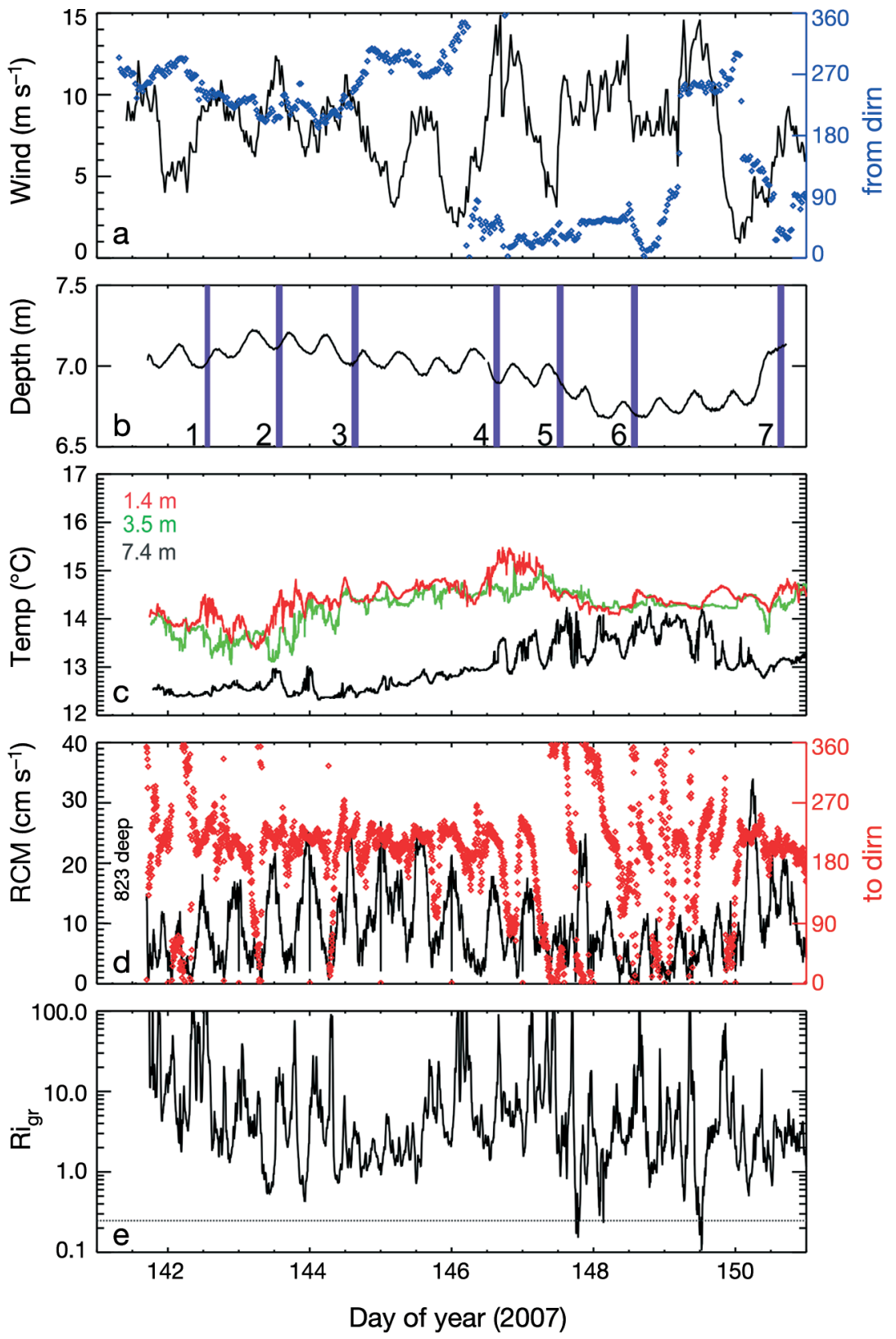

Fig. 3. Background data showing (a) wind speed and the direction from where it originates (from dirn), (b) water depth (at Stn 3) and times of transects (blue lines, described in 'Results' and see Fig. 10), (c) temperature time series from Stn 5 at 3 depths, (d) current meter (at 5.3 m depth, Stn 5) speed and the 'to' direction flow (to dirn) and (e) an estimate of the gradient Richardson number $\left(\mathrm{Ri}_{\mathrm{gr}}\right)$. The horizontal dotted line in (e) is the theoretical critical threshold for mixing $\left(\mathrm{Ri}_{\mathrm{gr}}=0.25\right)$. $\mathrm{RCM}$ : recording current meter (823 deep is current meter no.) 
8 to $9^{\circ} \mathrm{C}$ at night. This bracketed surface water temperatures that were in the range of 14 to $15.5^{\circ} \mathrm{C}$ (Fig. 3). Wind speeds during the field experiment were mostly low (Fig. 3a). The first 3 turbulence transect sampling days took place during the southwesterly winds period whereas the subsequent 3 transect days occurred during the northerly winds. The last transect took place during a period of wind shift. Interestingly, there were some reasonable differences in direction between the meteorological station in Nykøbing (Fig. 3) and at the field site (Table 3). The cloud cover was variable over the period with rain on transect Day 6. Although the wind speeds were mostly modest, on several occasions it exceeded $10 \mathrm{~m} \mathrm{~s}^{-1}$. The first of the strong wind events was from the north (day of year [DOY] 146) and so the field site was well protected from direct effects, although delayed changes then result from baroclinic gradients (Wiles et al. 2006). Following this, the site was exposed to a second wind event (DOY 149), which was from the WSW and so the site was less protected. Tidal influences generated water surface elevation variations of $0.15 \mathrm{~m}$ (Fig. 3b) whereas weather variations generated a comparable magnitude of change in elevation, but over longer time scales.

\section{Currents}

Currents at RCM Stn 5 (Fig. 2c,d) contained peaks in the vicinity of $20 \mathrm{~cm} \mathrm{~s}^{-1}$ (Fig. 3d) with a single event exceeding $30 \mathrm{~cm} \mathrm{~s}^{-1}$ (DOY 150). Generally speaking, this is insufficient to drive benthic boundary layer mixing strong enough to dominate other processes (Wiles et al. 2006), but it will generate canopy-driven effects. Separation of tide and wind influence was difficult as the wind field appeared to be diurnally driven over the first half of the experiment. The first half of the experiment with the diurnal wind variation resulted in the deeper current meter showing largely a southward flow that only occasionally swung to the north. This changed with the breakdown of the regular wind forcing in the second half of the experiment. The upper current meter was more evenly distributed in a north-south balance. Several of the large flow events appeared related to either the onset (DOY 146.8) or cessation (DOY 150) of strong winds.

In contrast to the outer RCM Stn 5, the ADCPs at stations within or directly to the south of the farm typically measured slower flow speeds in the mid water column (Fig. 4), presumably due to the effect of the canopy. The main channel (Stn 5) flow was larger by

Table 3. Summary of field conditions

\begin{tabular}{|c|c|c|c|c|}
\hline $\begin{array}{l}\text { Transect } \\
\text { day }\end{array}$ & $\begin{array}{l}\text { Time/date/ } \\
\text { day of year }\end{array}$ & Weather & $\begin{array}{l}\text { Tide, } \\
\text { flow }\end{array}$ & Notes \\
\hline 1 & $\begin{array}{l}12: 26-13: 42 \mathrm{~h} \\
22 \text { May } 2007 \\
142\end{array}$ & Slight northerly & $\begin{array}{l}\text { Flood, } \\
\text { southward }\end{array}$ & $\begin{array}{l}\text { Low overall dissipation rates; very similar buoyancy frequency, } \\
\mathrm{N} \text {, profiles everywhere }\end{array}$ \\
\hline 2 & $\begin{array}{l}12: 37-14: 48 \text { h } \\
23 \text { May } 2007 \\
143\end{array}$ & $\begin{array}{l}\text { Sunny, } \\
\text { weak southerly }\end{array}$ & $\begin{array}{l}\text { Flood, } \\
\text { southward }\end{array}$ & $\begin{array}{l}\text { Widely spread dissipation rates, northward (Stn } 7 \text { ) profile very } \\
\text { different to elsewhere. No clear depletion pattern; in fact, the } \\
\text { central station exhibited a peak in fluorescence although the } \\
\text { absolute levels were low }\end{array}$ \\
\hline 3 & $\begin{array}{l}14: 10-16: 30 \mathrm{~h} \\
24 \text { May } 2007 \\
144\end{array}$ & $\begin{array}{l}\text { Cloudy, } \\
\text { moderate } \\
\text { southwesterly }\end{array}$ & $\begin{array}{l}\text { Flood, } \\
\text { southward }\end{array}$ & $\begin{array}{l}\text { Higher dissipation rates than previous, outer (Stn 5) profile } \\
\text { different to elsewhere. No change in fluorescence }\end{array}$ \\
\hline 4 & $\begin{array}{l}14: 01-16: 19 \text { h } \\
26 \text { May } 2007 \\
146\end{array}$ & $\begin{array}{l}\text { Partly cloudy, } \\
\text { very weak } \\
\text { westerly }\end{array}$ & $\begin{array}{l}\text { Ebb-low, } \\
\text { confused/ } \\
\text { southward }\end{array}$ & $\begin{array}{l}\text { Widely spread dissipation rates; northerly profile } \\
\text { different to others. Depletion pattern opposite of expected }\end{array}$ \\
\hline 5 & $\begin{array}{l}11: 42-13: 34 \mathrm{~h} \\
27 \text { May } 2007 \\
147\end{array}$ & $\begin{array}{l}\text { Cloudy, rainy, } \\
\text { northeasterly }\end{array}$ & $\begin{array}{l}\text { Ebb, } \\
\text { northward/ } \\
\text { confused }\end{array}$ & $\begin{array}{l}\text { High and relatively consistent dissipation rates everywhere; } \\
\text { outer Stn } 5 \text { profile more strongly stratified than elsewhere. } \\
\text { Clear and sensible depletion pattern with high biomass }\end{array}$ \\
\hline 6 & $\begin{array}{l}12: 46-14: 56 \mathrm{~h} \\
28 \text { May } 2007 \\
148\end{array}$ & $\begin{array}{l}\text { Cloudy, rainy } \\
\text { and rising } \\
\text { north-easter }\end{array}$ & $\begin{array}{l}\text { Ebb, } \\
\text { northward/ } \\
\text { confused }\end{array}$ & $\begin{array}{l}\text { Slicks seen on this day. Clear and sensible depletion pattern with } \\
\text { highest biomass observed }\end{array}$ \\
\hline 7 & $\begin{array}{l}14: 16-16: 30 \mathrm{~h} \\
30 \text { May } 2007 \\
150\end{array}$ & $\begin{array}{l}\text { Sunny, easing } \\
\text { southwesterly }\end{array}$ & $\begin{array}{l}\text { Ebb, } \\
\text { southward }\end{array}$ & $\begin{array}{l}\text { Moderate dissipation rates; strongest stratification of the } \\
\text { experiment. Although this should have been on the ebb phase of } \\
\text { the tide, the elevation was not actually dropping (Fig. 3) }\end{array}$ \\
\hline
\end{tabular}




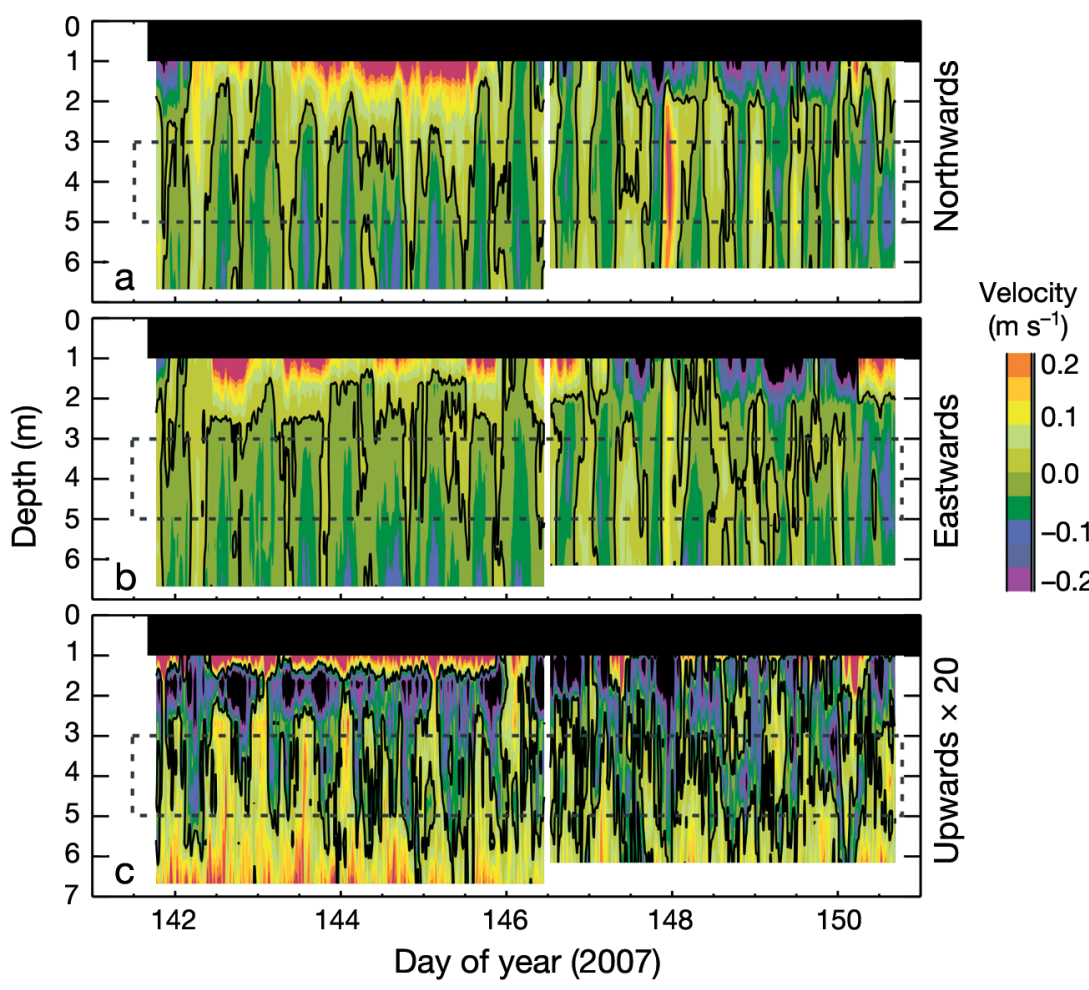

Fig. 4. The $1000 \mathrm{kHz}$ Nortek Aquadopp acoustic Doppler current profiler (ADCP) data. The instrument was moved from Stn 3 (center) to Stn 2 (south) at day of year 146.5. (a) Northward, (b) eastward and (c) upward components of velocity are shown. Note that in (c) the velocity is multiplied by a factor of 20 . Black regions represent the region of no reliable signal from the ADCP due to side-lobe effects. Dashed boxes show the approximate depth band where the crop is located

a factor of 2 than that within the farm (Fig. 5). Of course the farm effect cannot be separated from the bathymetric effect. For example, it was relatively common for the flow direction in the farm to oppose that seen in the main channel. It was expected that there would be some kind of wake effect and comparison of nearby Stn 2 (south) and Stn 3 (in-farm) would capture this. This comparison (Fig. 5) suggests that there was no obvious wake effect in the southward regime but that there appears to be a reduction in the magnitude of northward flows but no identifiable bias whereby the farm flow was weaker. However, there was one large event where the northflowing current speed at Stn 2 was almost double that at the in-farm station (Stn 3). There were many instances when the east-west components showed a form of return flow whereby the south station would be flowing westward whilst the in-farm station would sustain flow to the east.

Frequency analysis (Fig. 6) clearly shows a peak in kinetic energy at the semi-diurnal tidal frequency. Tidally induced current variability was of the order of $\pm 0.1 \mathrm{~m} \mathrm{~s}^{-1}$ whereas near-surface speeds (i.e. vector-summed velocity magnitude) exceeded $0.25 \mathrm{~m} \mathrm{~s}^{-1}$ (Fig. 4). This was approximately half that seen at a distance of $<100 \mathrm{~m}$ to the east of the farm (Stn 5 in Fig. 2c). There were substantially higher flows outside the farm (Fig. 3d vs. Fig. 4). This suggests a broad horizontal shear, which has implications for horizontal diffusivity (see the 'Discussion').

The gradient Richardson number (Eq. 1) was quite spiky and was dominated by a number of strong events (Fig. 3e). The vertical flows measured by the $1 \mathrm{MHz}$ ADCP (Fig. 4c) show probably the strongest change in signal inside vs. outside the farm. At the site to the south of the farm, the relatively large vertical flows are no longer present and the flow is far less regular in structure. The rising phases of the tide often brought with it a local peak in temperature and current magnitude (Fig. 3b-d). In addition, there were consistent variations in backscatter at tidal frequencies throughout the entire water column, with persistent increases near the bed and the surface (data not shown). The increase near the bed was presumably due to resuspension. The enhanced backscatter throughout the water column was possibly a redistribution of this resuspended material whereas the backscatter near the surface (but below the 10\% of depth cutoff) may be related to a more turbid but fresher layer of water. This resulted in good signalto-noise characteristics for the ADCPs.

\section{Temperature and salinity stratification}

The Stn 3 profile data viewed in temperaturesalinity space (Fig. 7) indicates large-scale temporal variability in the background stratification and the dominance of salinity in terms of dynamic contribution (i.e. it dominates the density signal). Furthermore, there was a relatively constant temperature vs. salinity slope (Fig. 7). The variability in background stratification can be viewed using spectra (Fig. 6) derived from the thermistor time series (Fig. 3c) where, at least from a thermal perspective, the surface half of the water column was close to homogeneous but with over a degree drop in temperature to the sensor 

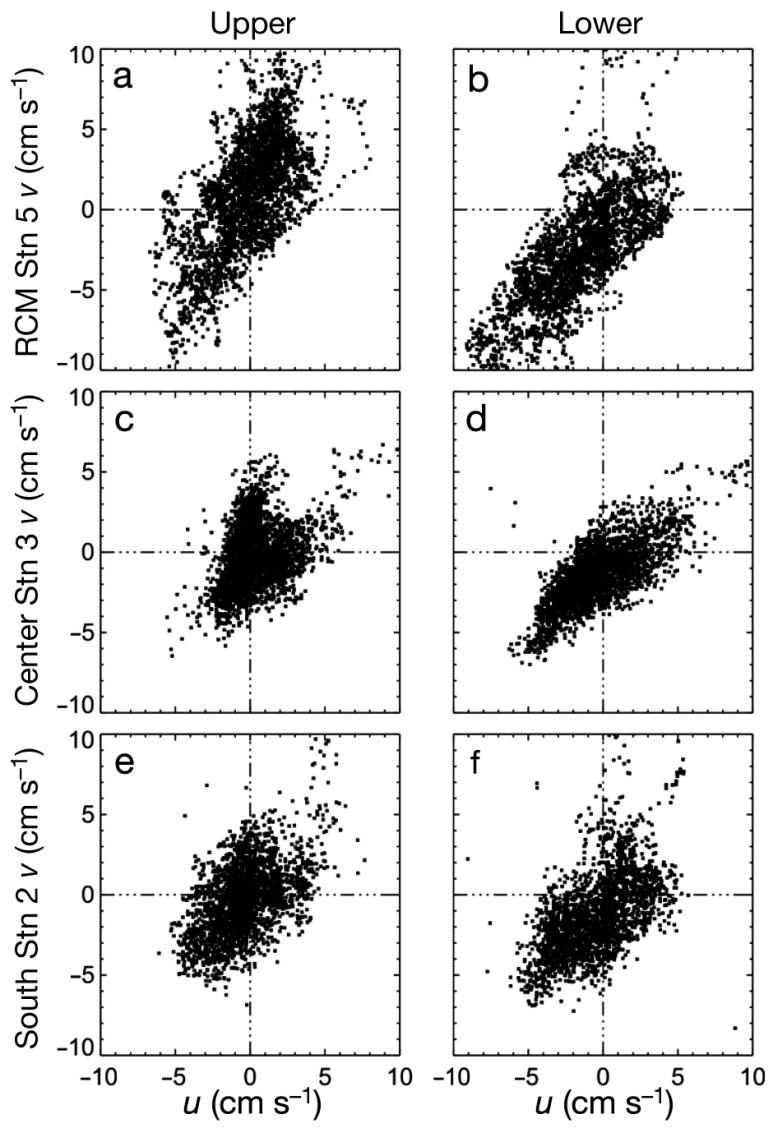

Fig. 5. Comparison of flows at upper (2-3 m) and lower (5-6 m) levels in the water column. Data were recorded at stations $(\mathrm{a}, \mathrm{b})$ RCM Stn 5, (c,d) farm center Stn 3, and (e,f) south of farm Stn 2. $u$ and $v$ are north-south and east-west Cartesian components where eastward and northward flows are positive

near the bed. Although this does not have as much dynamic significance as the salinity changes, the broadly consistent relationship between temperature and salinity (Fig. 7) implies that there will be a similar relationship with density. The spectra show also that only the deeper temperature sensor exhibited a strong semidiurnal $(12.45 \mathrm{~h})$ peak in the frequency spectra, with the upper 2 sensors having their signal dominated by variability at a range of scales.

An example microstructure profile (Fig. 8) revealed information on the temperature, salinity, density and fluorometric structure of the water column as well as the derived properties such as $N^{2}, \varepsilon$ and $K_{\mathrm{v}}$. These data sets are inherently spiky because of their ability to capture the smallest scales of variability. The temperature gradient variability captures the overturning temperature structure that is then analyzed to derive $\varepsilon$. Buoyancy frequency squared, shown in Fig. $8 \mathrm{~b}$, is strongly variable because it is a derivative property that tends to amplify small-scale variability in the original signal.

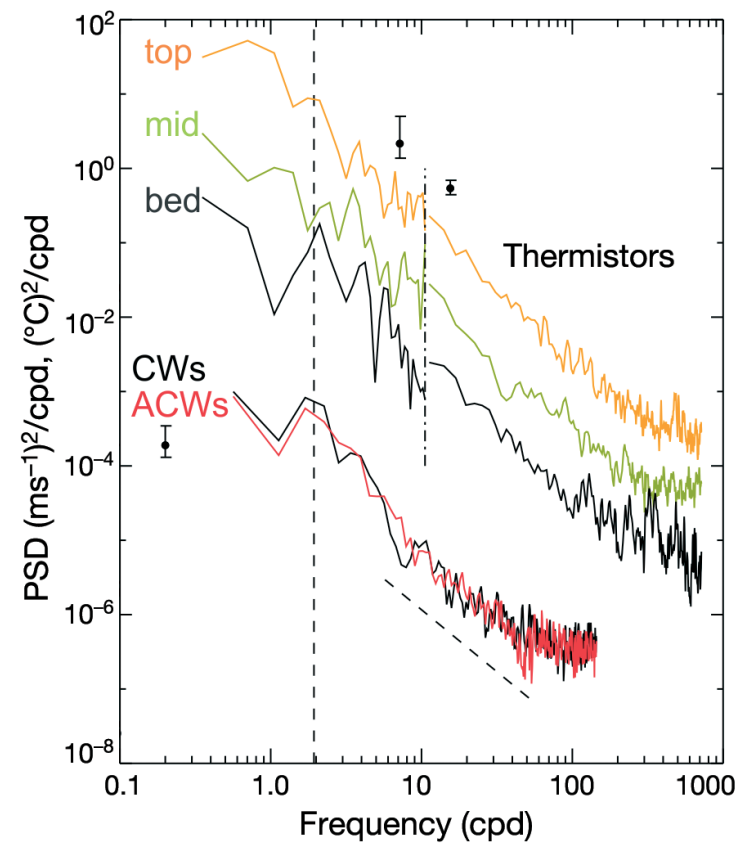

Fig. 6. Spectra from thermistors (upper 3 traces) and rotational spectra (ACW: anti-clockwise; CW: clockwise) for the deep current meter (RCM823-deep) at Stn 5. The vertical dashed line at nearly 2 cycles per day (cpd) shows the semidiurnal tide. The vertical dash-dotted line shows the separation between frequency analysis bins for the temperature spectra (with relevant 95\% confidence limits). The sloping dashed line shows the frequency ${ }^{-5 / 3}$ relationship for reference. PSD: power spectral density

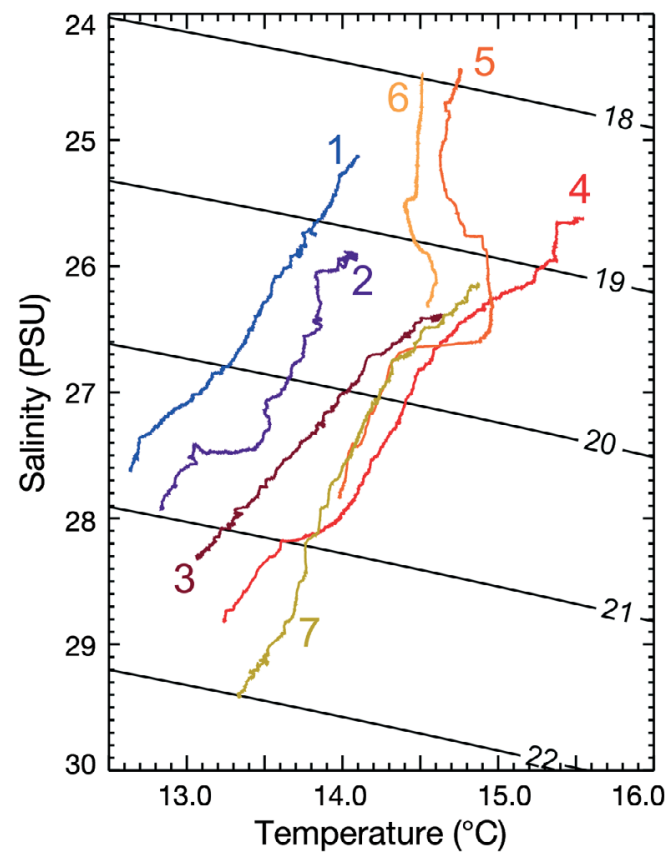

Fig. 7. Distributions of salinity as function of temperature from the microstructure profiles at the central (Stn 3) position for each sampling day (numbers). Background contours show density anomaly (i.e. $1000 \mathrm{~kg} \mathrm{~m}^{-3}$ ) 


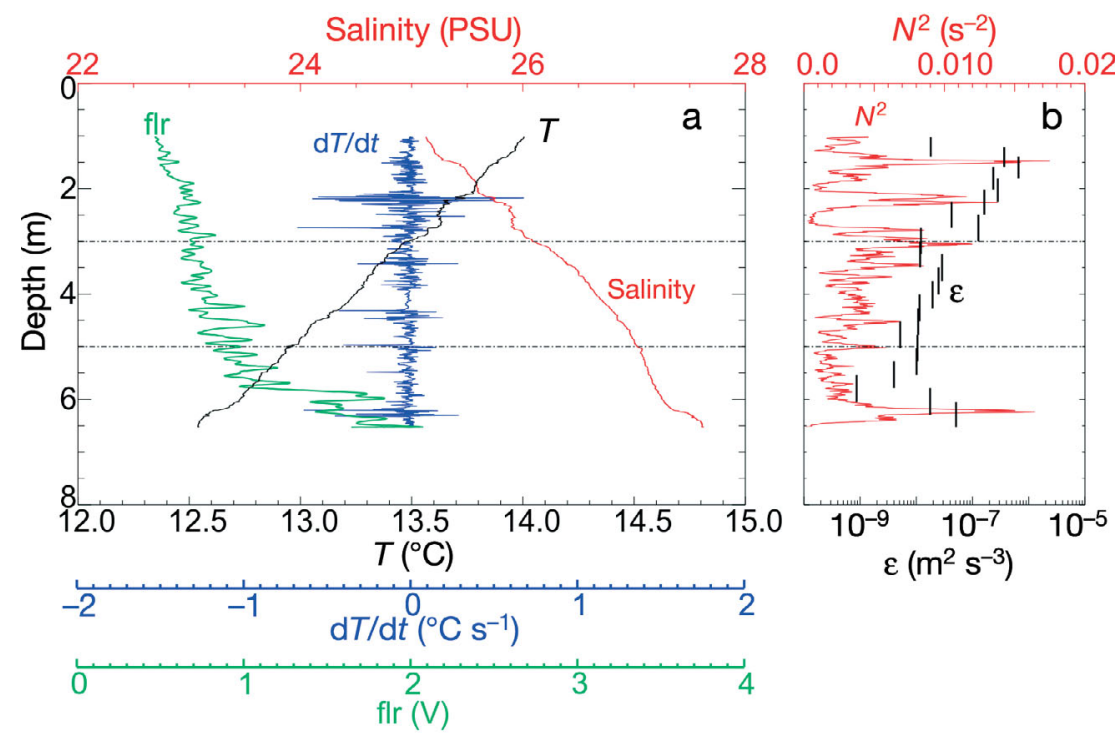

Fig. 8. Exemplary water column microstructure profile at Stn 3 on 22 May 2007 at 13:08 h. The profile structure includes (a) temperature $(T)$, salinity, temperature gradient microstructure $(\mathrm{d} T / \mathrm{d} t)$ and uncalibrated flourometer signal (flr, in V). The dot-dashed horizontal lines through both panels show the approximate locations of the top and bottom of the mussel loops. (b) Buoyancy frequency squared $\left(N^{2}\right)$ and turbulent kinetic energy dissipation rate $(\varepsilon)$, marked as vertical bars over their respective depth bins
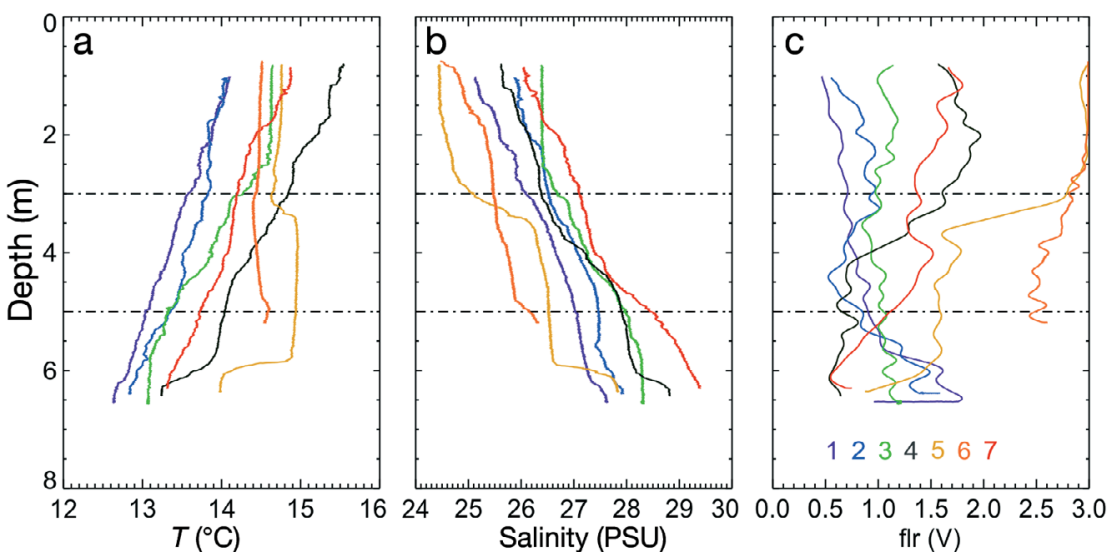

Fig. 9. (a) Temperature, (b) salinity and (c) fluorometer data (flr) from the central (Stn 3) station for all days. Transect Day number is colour coded (c). Dot-dashed lines as in Fig. 8

Near-surface layers (but deeper than the $1 \mathrm{~m}$ minimum sampling depth of the SCAMP) were observed consistently in the SCAMP data but there was little similarity from day to day (Stn 3; Fig. 9). Much of the time the density structure was quasi-linear. The station located centrally within the farm (Stn 3; Figs. 8, 9) provided the best indication of the presence of the shellfish crop, with local troughs in buoyancy frequency at a depth just below the top $(3 \mathrm{~m})$ of the crop. It is possible to build up quasi-spatial transects of profiles to provide a horizontal perspective on the stratification. An exemplary transect (Day 7;
Fig. 10) shows an evolution of salinity through the farm as well as relative to the structure outside the farm.

\section{Fluorescence}

The fluorometer signal typically contained a gradually moving background due to a near-continuum in small phytoplankton with occasional signal spikes when large individuals or phytoplankton aggregates passed through the sensor. This is different to the thin layers process in that these peaks were transient and likely associated with individuals rather than a coherent population constrained by stratification (e.g. Steinbuck et al. 2009). The fluorescence profiles look quite similar qualitatively (Fig. 9c) except for transect Day 5, when there was a well-defined layer of fluid at 3.5 to $6 \mathrm{~m}$ with a strong step in fluorescence data; Day 6 also had substantially elevated fluorometer levels, but over the complete depth. Data from the 'typical day' (Day 7; Fig. 10) suggest that there was some depletion within the farm, with lower fluorometer readings inside compared with outside the farm. This was not consistently apparent on other days. The typical day also shows a general trend in baroclinic structure, which is likely due to background conditions rather than a direct farm effect. The integrated SCUFA fluorescence data reveal some consistent patterns from day to day (Fig. 11). In order to simplify the patterns the inshore, northern and RCM stations (S1, S7, and S5, respectively) were omitted from the transects. It appears that the change in weather was also accompanied by inflow of more nutrient-rich water. Transects 1 and 3 are commensurate with the notion of depletion as flow moves through the farm (Fig. 11b). However, transects 2 and 4 do not obviously fit this picture. It could be that during the transect currents were turning, or otherwise changing in structure, and that this could explain the contradictory results on those days. The 2 days with higher fluorometer readings were the least saline of the profiles. 

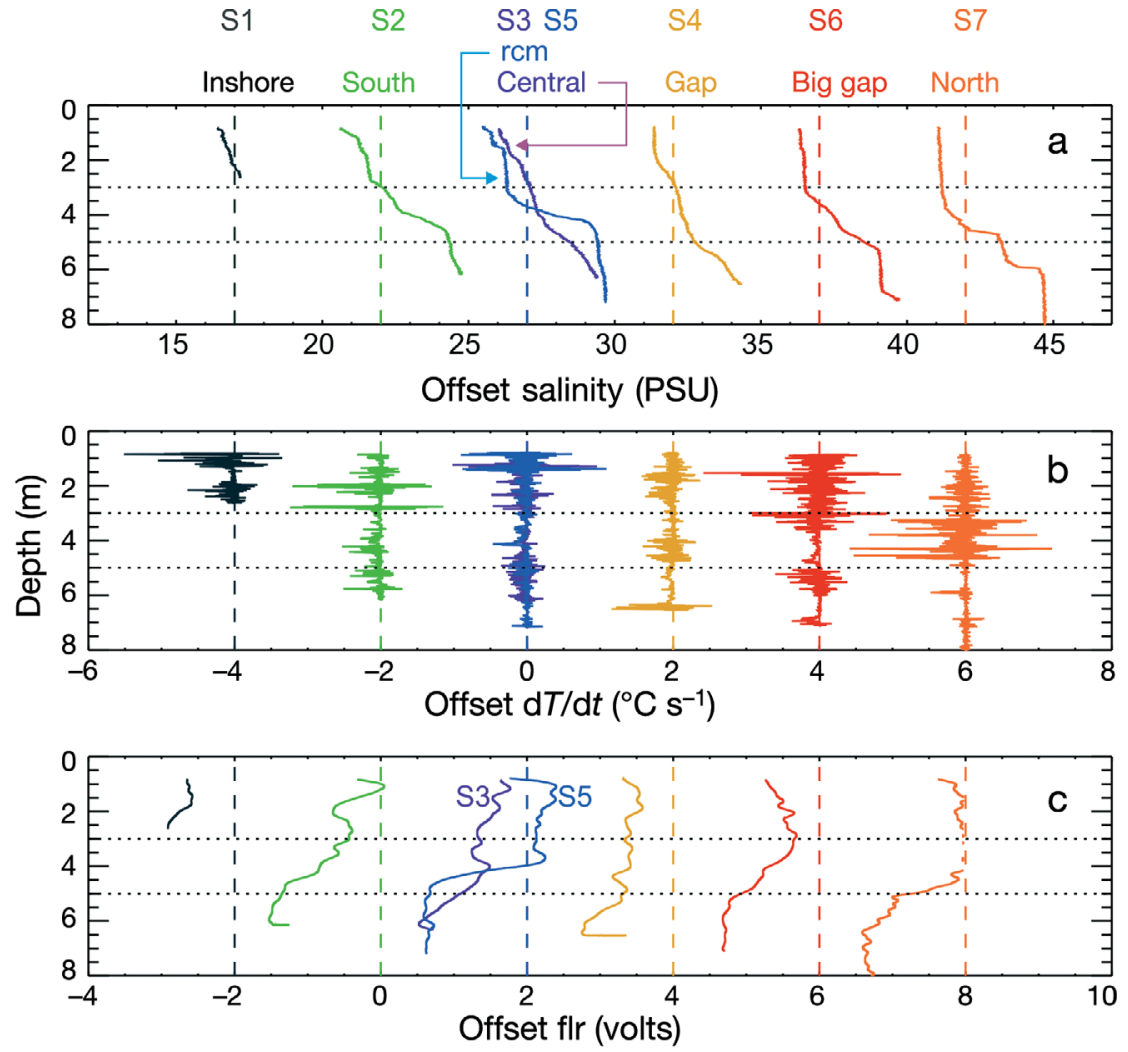

Fig. 10. Exemplary composite transects of (a) salinity, (b) temperature gradient microstructure $(\mathrm{d} T / \mathrm{d} t)$ and (c) fluorometer signal for transect Day 7 when flow was southwards. Note that the RCM (Stn 5) and central (Stn 3) profiles are superposed upon one another. Horizontal lines as in Fig. 8

versely, during periods of strong wind, wave effects dominated the velocity spectra. The wave effect raises a potentially important point relevant to the present focus on production and feeding - the role of waves in influencing mussel growth. Fig. 14 shows exemplary velocity spectra with and without the presence of surface waves. In enclosed systems such as Skive Fjord, waves are short wavelength and so have little penetration into the water column (perhaps $2 \mathrm{~m}$ at most). Because the floats are locked to the water surface to a large degree, there is still substantial motion of mussel relative to local water, and much of it is in the vertical direction. Some good estimates of $\varepsilon$ were resolved (Fig. 15), and these indicated a mean value of $\sim 10^{-7} \mathrm{~m}^{2} \mathrm{~s}^{-3}$. This falls within the range identified by the SCAMP estimates (Fig. 12). However, there was no clear trend with flow speed or direction. Quality control removed most estimates that were not flowing southwest. Remarkable, there was no correlation with flow speed; however, the farm effect dominated, so that the flow

\section{Turbulence}

Bin-averaged turbulent kinetic energy dissipation rate $\varepsilon$ resolved from the SCAMP profiler ranged between $10^{-8}$ and $5 \times 10^{-6} \mathrm{~m}^{2} \mathrm{~s}^{-3}$ (Fig. 12). Bin-averaged vertical diffusivity $K_{V}$ for 3 stations (south Stn 2, center Stn 3 and outside Stn 5) was resolved from these data (Fig. 13) and ranged between $10^{-6}$ and $10^{-2} \mathrm{~m}^{2}$ $\mathrm{s}^{-1}$. A variety of diffusivity profile structures were observed, ranging from consistently low (Day 7) to consistently high (Day 6) rates of vertical mixing. Other days saw highly variable mixing rates (Day 2) or clearly stratified mixing rates (Day 5). There was no consistent farm signature, although the southward flow during Day 3 resulted in higher mixing near the farm, the southernmost (i.e. in the wake) station having some of the highest mixing rates (except near the bed) of the entire experiment.

The velocimeter measurements struggled to resolve many high-quality estimates of $\varepsilon$. This was due to a combination of effects, whereby many estimates fell beneath the noise floor of the technique or, con- speed that was being used as a correlate was not independent of the dissipation rate estimate.

\section{DISCUSSION}

Here we consider the questions posed in the 'Introduction' in the context of seeking to understand the fundamental importance of the interplay between turbulence and stratification.

\section{Farm-driven flow and stratification variation}

In earlier work in a different part of the Limfjorden, Wiles et al. (2006) found that solar radiation and wave stirring were the dominant mixing processes in the more exposed areas. Such processes will undoubtedly be spatially heterogeneous. Furthermore, these authors identified that convective overturning would also have a substantial effect in winter. This variability manifests itself strongly and over 

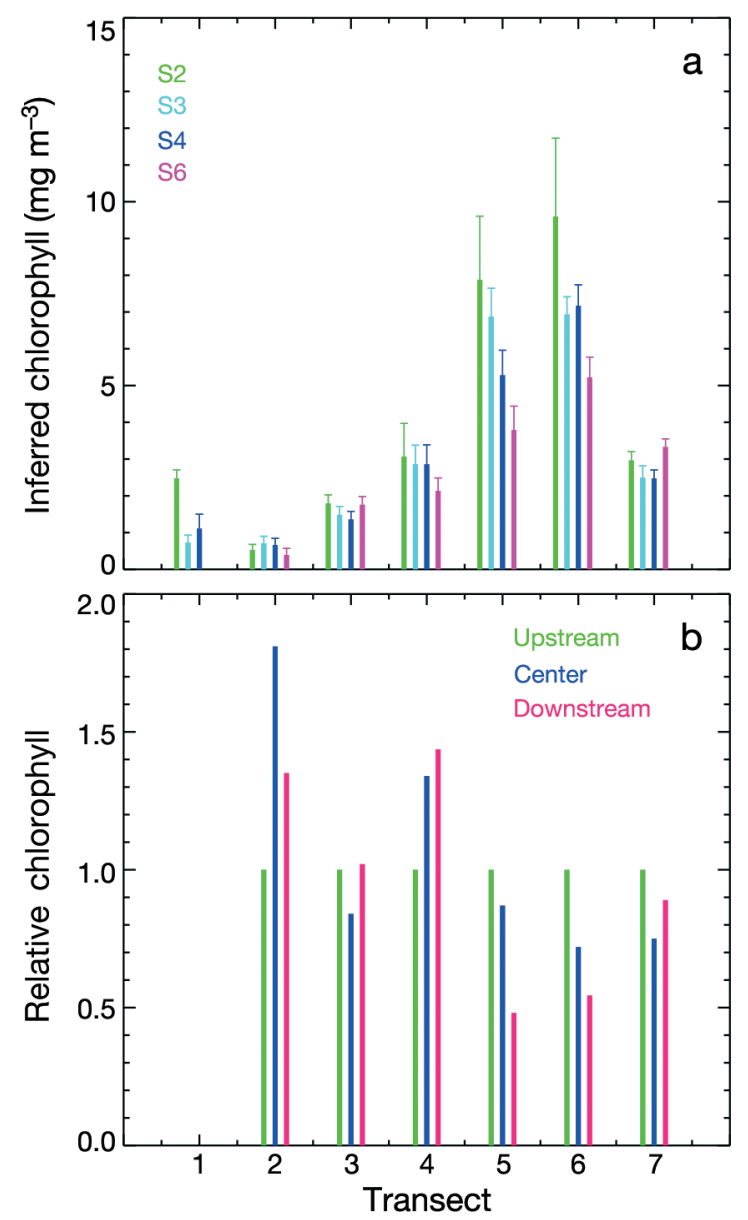

Fig. 11. SCUFA fluorescence data showing (a) station means $( \pm \mathrm{SD})$ of fluorescence-derived biomass (inferred chlorophyll) from the calibrated SCUFA averaged over the depth of the crop and (b) the depletion proportion (relative chlorophyll). For each transect day the stations were sorted based on whether they were upstream or downstream of Stn 3 (using the current meter observations) and then normalised relative to the chlorophyll reading at the upstream station

short time scales, as only 2 of the days observed in the present study had commonality in temperaturesalinity space and few of the lines even intersected (Fig. 7). Presumably, different parts of the Limfjorden, with their wide-ranging freshwater and oceanic inputs, mix and heat and cool in different ways, resulting in horizontal variability in density that is advected by tides, wind and buoyancy-driven readjustment (Wiles et al. 2006). This viewpoint illustrates the dominant dynamic role played by salinity, although the water column was also stably stratified in temperature. Although this might seem an unsatisfying result from the perspective of simple deterministic predictive rules, it does place a strong emphasis on understanding the underlying local estuarine oceanography.
A related question is whether our measurements actually show the farm effect. In reality, everything we measure likely exhibits some farm effect because of the influence of pressure gradients and localized mixing. We cannot be definitive about farm effect unless we have a parallel equivalent no-farm system upon which to conduct the same measurements. Numerical modeling is the only tool available to look at such effects (e.g. Fan et al. 2009, Plew 2011), but these models need some basis for their choice of scales and against which to be validated. For example, it is likely that the presence of the farm would influence the secondary flows (i.e. departures from a tidal ellipse) seen in Fig. 5 so that a model would be able to resolve this scale.

An important aspect of the farm effect is how the stratification is distorted as the fluid moves through and past the farm. The stratification will be affected by both direct mixing and pressure gradients. Plew et al. (2006) indicated that the presence of the crop lines should be sufficient to significantly mix the water column. Profile data here certainly indicate that such mixing can happen (Fig. 10) and that the observed levels of turbulence are sufficient to create substantial eddies. The $N^{2}$ at center Stn 3 was observed to be $\sim 10^{-3}$ to $10^{-2}$ (rad s) $)^{-2}$ (Fig. 8), and with shear $S$ reaching $0.1 \mathrm{~s}^{-1}$, this gives a minimum $\mathrm{Ri}_{\mathrm{gr}}=0.1$, so mixing would have ensued occasionally, but the majority of the time $\mathrm{Ri}_{\mathrm{gr}} \sim 1$ to 10 , indicating local stability (Fig. 3e). Applying the Plew et al. (2006) scaling argument (Eq. 2) to the present situation suggests that the isopycnal deflection should be approximately $4 \mathrm{~m}$ $\left(N=10^{-2} \operatorname{rad~s}^{-1}, \alpha=0.5, U_{0}=0.1 \mathrm{~m} \mathrm{~s}^{-1}, H_{\mathrm{C}}=2 \mathrm{~m}\right)$. This is comparable to the depth of water column not occupied by the shellfish crop. As with Plew et al. (2006), this large vertical deflection suggests that gradients in stratification are moving away from the farm.

\section{Effect of farm heterogeneity}

A shellfish farm is heterogeneous at a variety of scales. First, the crop-bearing vertical elements do not extend to the full depth of the water column (Plew et al. 2006). Second, these elements are distributed in rows of longlines, enforcing heterogeneity at approximately the $15 \mathrm{~m}$ scale. Third, there are small gaps between the blocks of rows $(\sim 30 \mathrm{~m})$. And finally, there are the occasional large gaps ( 150 m) between farms. These gaps are in the horizontal rather than vertical dimension (Folkard 2011).

Consideration of the profile data suggested that there were greater differences between the out-of- 

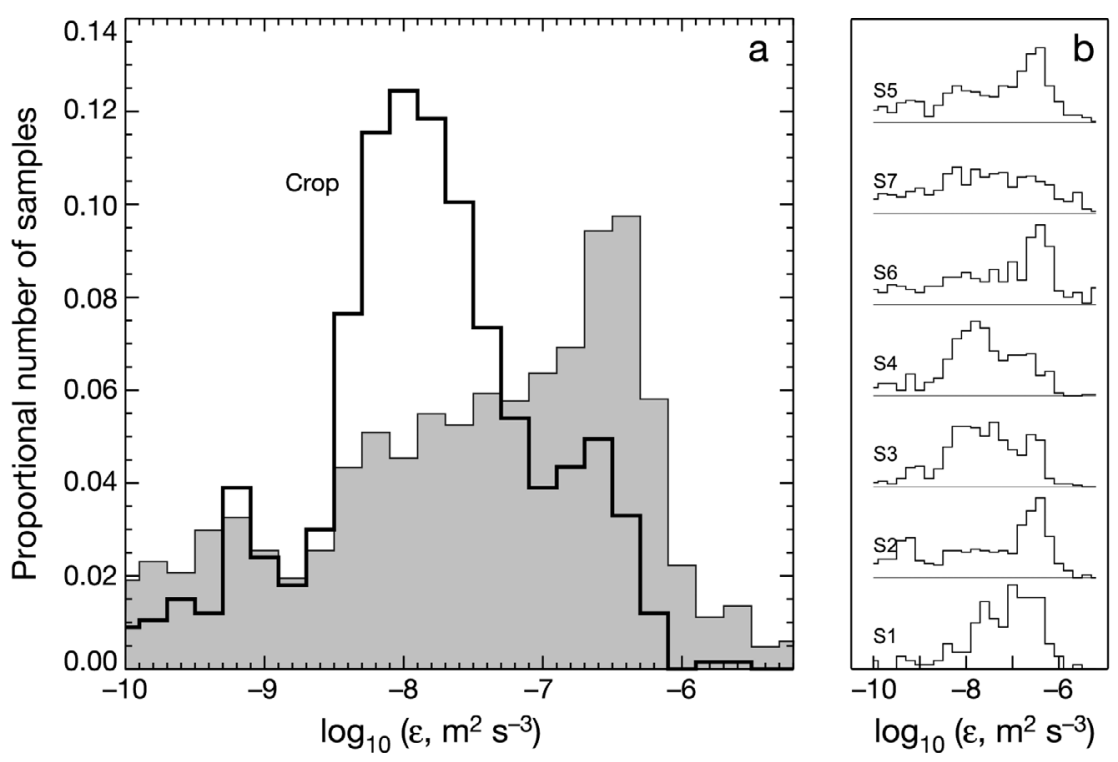

Fig. 12. Histograms of dissipation rate $(\varepsilon)$ derived from the SCAMP profiler data segments (a) near-crop (open histogram) and away from near-crop (shaded histogram), and (b) distributions for each station, roughly ordered from far to near (top to bottom)

farm Stn 5 and the general farm structure than the difference between the gap profiles (Stns 4 and 6). Any crop-driven variation in water column density structure generates baroclinic flows (Jamali et al. 2008), which, to first order, propagate at a baroclinic long wave speed $N H$ ( $H=$ total water depth). Typical estimates for this speed are $\sim 0.1 \mathrm{~m} \mathrm{~s}^{-1}$, which means any flow due to variation in mixing would cover the 30 and $150 \mathrm{~m}$ gaps in times of 300 and $1500 \mathrm{~s}$, respectively, i.e. short compared with tidal and weather time scales. This flow is comparable to the local circulation speeds except at peak tidal flows. The presence of small gaps likely does not alter this densitydriven exchange as the density structure would not change substantially before the next part of the farm was encountered by the flow. However, larger gaps might do so (Fig. 16a). The next step would be to identify the actual critical scale at which this behaviour changes. If turbulence collapses on a time scale of $\sim 1 / N$ and the flow is advected at speed $u$, then a critical length scale is $L_{\mathrm{c}}=2 \pi u / N$, which for $u=0.1 \mathrm{~m}$ $\mathrm{s}^{-1}$ and $N=0.01 \mathrm{rad} \mathrm{s}^{-1}$ suggests a distance of $\sim 60 \mathrm{~m}-$ intermediate between the 2 gap sizes considered here. Hence gaps in farm structure would drive heterogeneity in structure-induced mixing, which would in turn generate variability in density and so drive horizontal exchange flows (Fig. 16a).

Generation of horizontal velocity shear will have an effect on shear dispersion by the farm as a whole, and is also likely to have some effect on in-out farm exchange (Grant \& Bacher 2001). The horizontal shear can be inferred from the differences in the data presented in Fig. 5a and b, where there is an $\sim 5 \mathrm{~cm} \mathrm{~s}^{-1}$ difference in flow magnitude based on sampling locations $200 \mathrm{~m}$ apart, suggesting a shear of $0.0025 \mathrm{~s}^{-1}$. Estuarine models will generate this process if they are able to resolve the shear and have some horizontal diffusivity, even if only numerical.

\section{Turbulent diffusion}

Turbulent mixing needs to be considered from 2 interrelated perspectives: horizontal and vertical. At the farm scale, the horizontal mixing within a farm will be a balance of enhanced mixing due to the presence of crop elements relative to the decreased available kinetic energy due to the general slowdown in the canopy flow. Instead of increased mixing in the middle of a dense farm, the flow reduction appears to be sufficient to have the opposite effect. Pilditch et al. (2001) considered seston supply using an advection-diffusion approach with an anisotropic diffusivity (along-farm diffusivity 10 times acrossfarm diffusivity). Scaling suggests $K_{\mathrm{h}}=u L=0.1 \times$ $15=\sim 1 \mathrm{~m}^{2} \mathrm{~s}^{-1}$ if longlines cause eddies, which is around a factor of 10 smaller than the value used by Pilditch et al. (2001). Their estimates were taken from mechanistic arguments rather than the mix of empirical observation and known scales used here. It is likely that bathymetry and environmental factors dominate diffusion levels. For example, in the present study, the constriction at the SundsøreHvalpsund narrows dominated flow variability, generating separation, eddies and recirculation in southward flow and strong convergence in northward flow. In this case, one might take the length scale to be closer to the basin width so that $K_{\mathrm{h}}=u L=0.1 \times$ $1000=\sim 100 \mathrm{~m}^{2} \mathrm{~s}^{-1}, 10$ times larger than the Pilditch et al. (2001) value. Ideally, from a modeling perspective, the model would have sufficient spatio-temporal resolution to reflect the flow separation seen in the narrows and could use the smaller diffusivity to represent processes at the sub-farm scale (i.e. Grant \& Bacher 2001). 


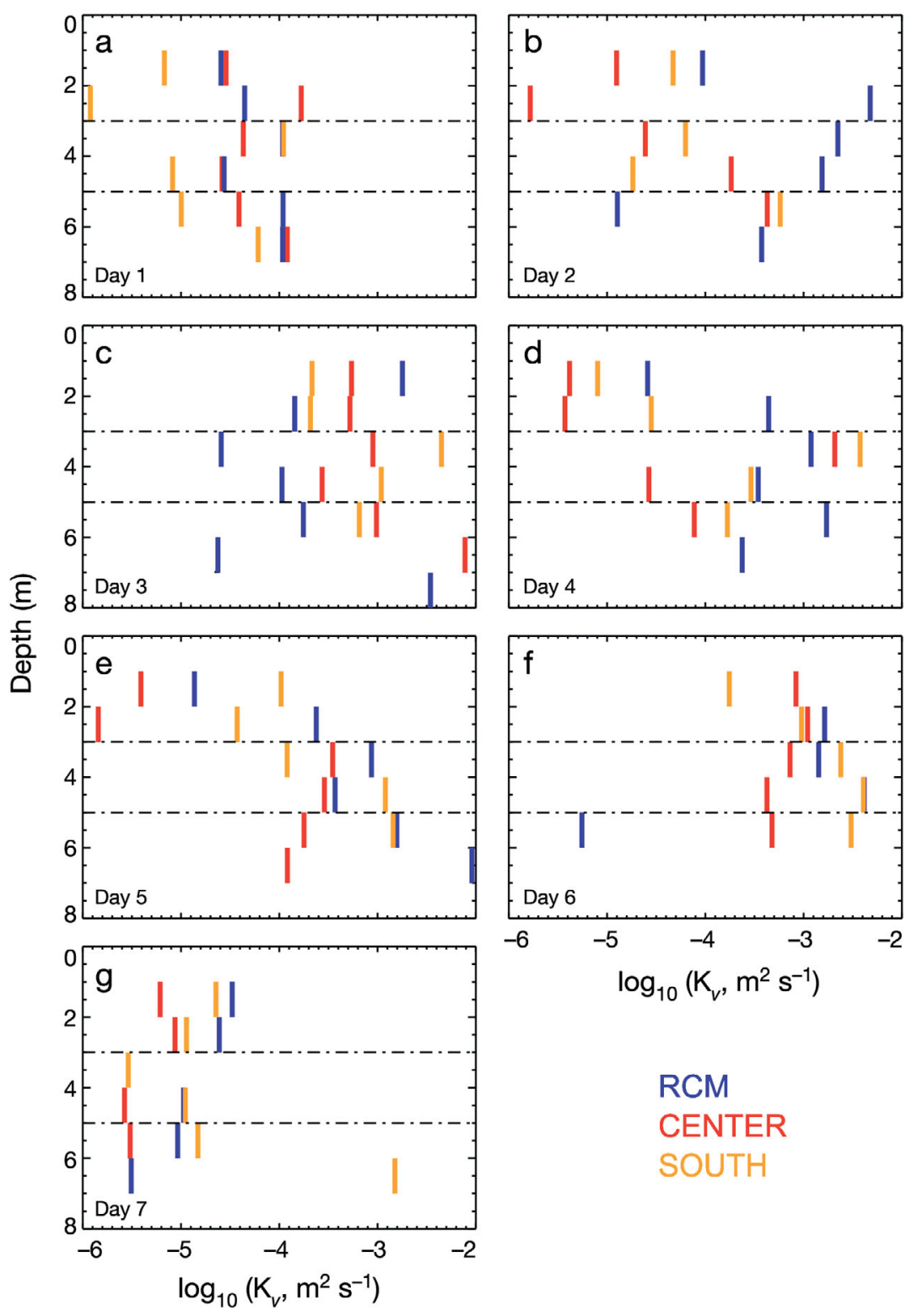

Fig. 13. Bin-averaged vertical diffusivity $\left(K_{\mathrm{v}}\right)$ for all days at 3 stations (south Stn 2, center Stn 3 and outside Stn 5). Each bar shows the vertical extent of the bin average, which contains all the data from each triplet of profiles that fall within that depth range. The horizontal dot-dashed lines show the regional of the mussel dropper zone. RCM: recording (at Stn 5) current meter

et al. 2011) illustrates how variable the flow is in any instantaneous sense and the challenge is capturing the strong events. A difference between sites in the SCAMP turbulence data (Fig. 13) was the stronger vertical density stratification at the mooring (Stn 5). This could be due to water depth, proximity to shore or the presence of the shellfish farm. Clearly, the Limfjorden is a complex system, but so are most coastal waterways that are characterized by variable topography, tides, stratification and weather effects (e.g. Nikora et al. 2002).

\section{Food availability}

There is evidence (e.g. Fig. 10c) that substantial baroclinic gradients persist between the canopy and the background flow. Transect 7 shows a nearly linear salinity stratification evolving along the canopy axis whereas the outer RCM Stn 5 sustains a nearly 2-layer structure centered almost exactly at mid-crop depth. There is no strong evidence to suggest that this interface is at mid-crop depth for a canopy-driven reason. Regardless of its cause, it would result in a baroclinic exchange flow whereby the continuously stratified fluid flows into the interface band, with concomitant return flows above and below.

Considering the roles of turbulence and mixing, at the individual mussel scale, inhalation occurs via a potential flow whereas the fluid is exhaled as a jet flow, thus even in the absence of any cross flow there is exchange (O'Riordan et al. 1995). Plew et al. (2009) looked at this process from the

The vertical mixing was directly measured here using temperature gradient microstructure. It has been demonstrated (Plew et al. 2006) that it can be difficult to resolve the influence of shellfish farms on microstructure turbulence parameters. This has been explained previously as being due to inherent intermittency in the turbulence coupled with the structural variability. Consideration of the multiple wake structure inherent in flow-past multiple cylinders (Delaux perspective of its influence on local drag coefficients, but in the absence of stratification. Stratification tends to compress this behaviour into a horizontal domain, thereby influencing the likelihood of refiltration. The upstream feeding vertical length scale is a selective withdrawal process (Imberger et al. 1976) and a function of feeding ingestion flow rate and stratification (Fig. 16c). The strength of this selective withdrawal must be considered in the light of back- 


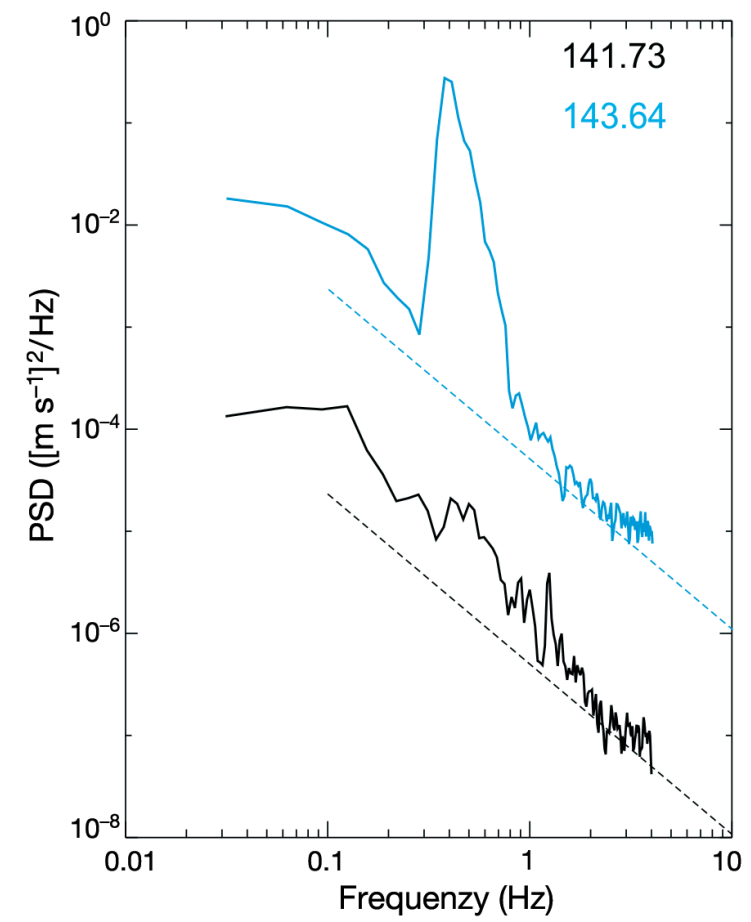

Fig. 14. Velocity spectra from near Stn 3 from times with (blue, offset vertically by $10^{2}$ ) and without (black) wave activity. The sloping dashed lines show a frequency ${ }^{-5 / 3}$ slope marking where useful estimates of dissipation rates could be resolved as described in 'Results: Turbulence'. Blue and black numbers in the top right corner are days of year (2007). PSD: power spectral density

ground mixing. The $L_{\mathrm{Oz}}$ indicates eddies in the vertical reaching $\sim 30 \mathrm{~cm}\left(\varepsilon=10^{-7} \mathrm{~m}^{2} \mathrm{~s}^{-3}, N=0.01 \mathrm{rad} \mathrm{s}^{-1}\right)$, so not that large. Thus, with many mussels adjacent to one another, the feeding/withdrawal envelopes, over which food was gathered by individual animals, would overlap (Ackerman \& Nishizaki 2004, van Duren et al. 2006). This implies that a depleted zone would persist in time so that having different areas of the farm at different depths would maximize exposure to nutrients if they were found to be limiting. This has some relevance to the thin layers phenomenon, whereby populations are concentrated into narrow vertical bands (e.g. Steinbuck et al. 2009),

\section{Farm design}

There is a marked difference between the present system and those found in more offshore waters, e.g. those in New Zealand, where even those farms considered sheltered would be much more exposed to oceanic conditions than the Limfjorden site. This is interesting because the turbulence dissipation rates measured in the Limfjorden farm were generally

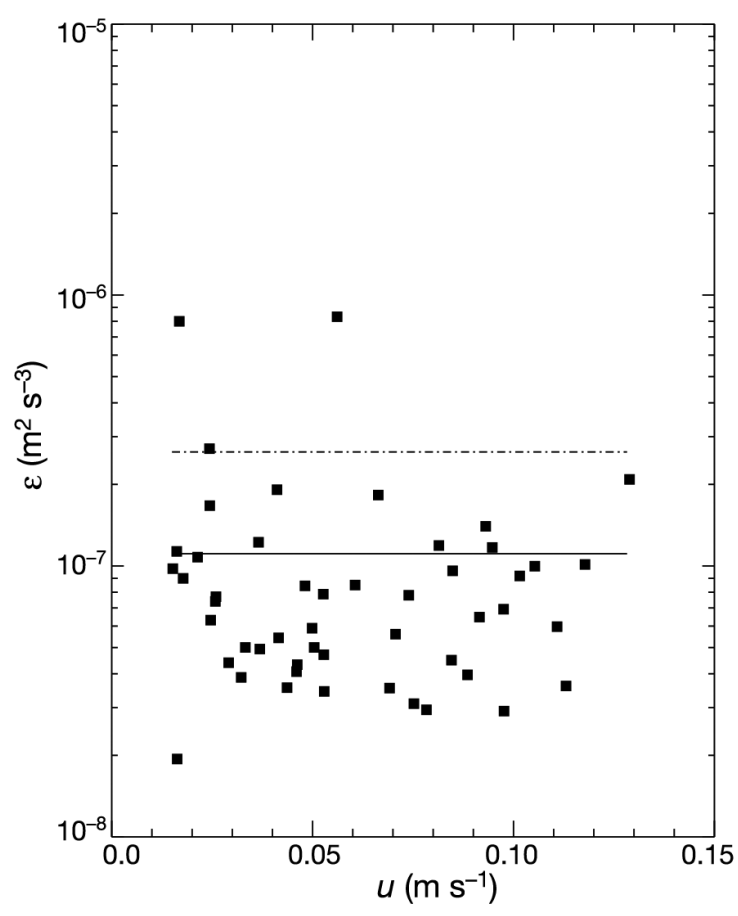

Fig. 15. Dissipation rate $(\varepsilon)$ estimates from the Vector velocimeter as a function of flow speed $(u)$. Only those values that passed a goodness-of-fit test are shown. The solid and dash-dotted horizontal lines show the mean and mean + SD values, respectively, for all good estimates

larger than those observed in Golden Bay, New Zealand (Plew et al. 2006). This might point to the shallower water, estuarine conditions or denser cropping or the proximity of strong bathymetric (i.e. the Hvalpsund constriction) variation seen in the Danish system, because certainly the flows were faster and waves were longer in the New Zealand farm. Clearly, at the large scale there are benefits of selecting farm locations with favourable flow-driven flushing properties. Reliable basin-scale modeling will make these properties more accurately assessed.

One site-dependent aspect is crop exposure to nutrients. In the highly eutrophic system examined here there is perhaps little to be gained from maximizing this exposure. However, some forward thinking is required. For example, as is the case here, the high aquatic nutrient levels are largely due to terrestrial farm activity. As tighter controls and improvements in land-based farm practices become the norm, nutrient injection into coastal systems will be reduced. Thus the shellfish farm operators must plan for a time when nutrients will not be so readily available.

Stratification plays a large role in redistributing material. The patterns of seston with regard to water depth remain to be determined, as, at least over the time sampled here, the system is highly variable. 


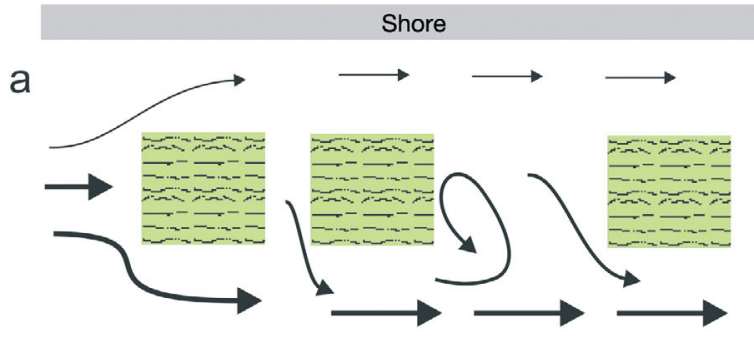

b

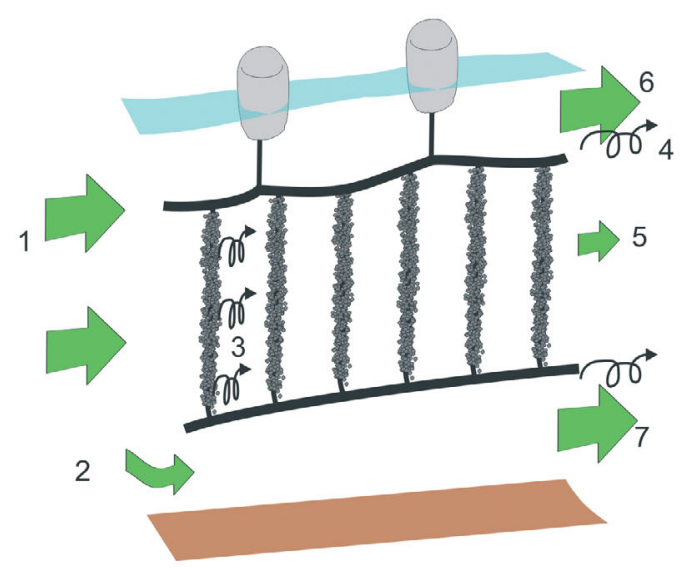

C

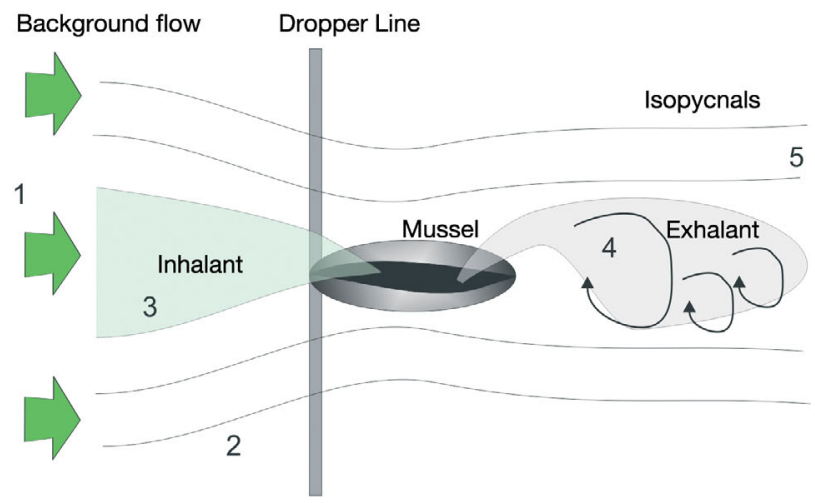

Fig. 16. Interpretive sketches. (a) Farm scale, showing a 3-block farm unit from above with small and big gaps and hypothetical flow (arrows; the thicker the arrow the stronger the flow). (b) Intermediate scale, showing flow and turbulence around a longline section showing (1) incoming flow, (2) underflow, (3) mussel-line induced turbulence, (4) shearinduced turbulence, (5) flow reduction and accelerated flow (6) above and (7) below the mussel crop. (c) The near-mussel flow, showing (1) inflow, (2) upstream isopycnals, (3) fluid being inhaled by the siphon action and (4) then exhaled, and (5) the deformed downstream isopycnals. Green and black (curly) arrows in $(\mathrm{b}, \mathrm{c})$ indicate mean flow and turbulent flow, respectively

Clearly the crop does not instantly mix the water column even at the depth of the crop. Thus, stratification persists and so nutrient availability will be confined in the vertical. Therefore, staggering of depth of crop will expand the depth range filtered by the canopy (Fig. 16b). The vertical diffusivity was not so great that mixing immediately evened out any depletion.

The role of vertical diffusion determined using arguments similar to those in Eq. (4) can be made for vertical diffusivity, whereby the filtration term is replaced by a volume flux. Thus the ratio of the time to remove nutrients from the cropped space via vertical diffusion $\left(\tau_{K}\right)$ vs. the time required for the space to fill due to advection $\left(\tau_{u}\right)$ is:

$$
\frac{\tau_{K}}{\tau_{u}}=\frac{H_{c}}{L} \frac{\delta u}{K_{V}}
$$

where $\delta$ is the vertical length scale of the mixing layer (the turbulent zone between density-separated layers moving relative to one another) and here we have assumed this is $\sim 1 \mathrm{~m}$. For values of $K_{\mathrm{v}} \sim 10^{-4} \mathrm{~m}^{2} \mathrm{~s}^{-1}$, the ratio $\tau_{K} / \tau_{\mathrm{u}}$ evaluates to around 10 so that advection dominates. If, say 10 farms were placed end to end or there was far greater vertical mixing, then this estimate indicates that vertical diffusion might indeed become important. An alternate strategy to staggering in the vertical might be to arrange the longlines perpendicular to the flow to enhance vertical shear and mixing. With regard to heterogeneity, increasing the gap size between blocks may result in increased production or a shortening of the lines required for existing production.

Demonstrably there is flow variability at the canopy scale. This can be modified by varying the density of the crop distribution (Smith et al. 2006). There will then be a feedback whereby variability in crop will then influence the growth of the crop itself (Brigolin et al. 2008). The present results illustrate the variability in the system and generate challenges to identification of systematic ways to improve production. However, there are a number of issues that can guide farm structure. If there were some consistent inferences to be drawn around seston over seasonal cycles, then the farm structure could be modified to make the greatest use of this. This suggests that there is a great need to develop a reliable picture of annual stratification.

\section{Concluding remarks}

This observational study considers a number of aspects of flow complexity around shellfish farms in shallow estuarine systems. Several key issues emerge. Despite the canopy forming a definite obstacle, the response of the surrounding waters is complex and highly variable. It is not a simple matter to 
define the 'farm effect' and its spatial envelope. Accordingly, the turbulence and vertical mixing of material also is not well defined around a farm, at least when probed with point-measurement techniques used here.

Because the presence of the crop is insufficient to mix the water column in the vertical, at the canopy scale, production will clearly benefit from placing the mussels at the best local seston levels. The challenge then is to have a quantitative measure of this depth as a function of season, and either adjusting the canopy with the seasons or staggering the canopy in general to spread the feeding and depletion over the water column. This requires a good understanding of the background stratification and its drivers, even in the absence of considerations of the farm effect. A long-term understanding and description of variability in conditions in such waters is required before many useful production enhancement decisions can be made.

Future work should be connected to the 3 primary scales. At the basin scale, validated modeling using adequately described diffusivities is required to help describe and predict conditions over long time scales. At the canopy scale, spatio-temporal mapping is required under a variety of conditions to determine the canopy effect on water column structure (Cranford et al. 2008) and thus provide input into the largescale model for dynamics. Maps of flow distribution would provide a picture of the canopy influence and related effects such as heterogeneity. This proves challenging (Plew et al. 2005) because of the acoustic interference generated by the canopy as well as short-term variability. At the mussel scale, further experiments are required to determine the effect of near-mussel mixing and how this is influenced by flow and waves.

Acknowledgements. The authors thank the Royal Society of New Zealand International Science and Technology for travel funding, the New Zealand Foundation for Research Science and Technology Aquaculture Sustainability Programme, the Danish Government-funded Mumihus Project, D. Tøring and staff at the Danish Shellfish Centre, J. Larsen, the National Environmental Research Institute and Aanderaa Instruments. S. Delaux, D. Plew, J. O'Callaghan, B. Hayden and 3 anonymous reviewers all contributed to improving the paper.

\section{LITERATURE CITED}

Ackerman JD, Nishizaki MT (2004) The effect of velocity on the suspension feeding and growth of the marine mussels Mytilus trossulus and M. californianus: implications for niche separation. J Mar Syst 49:195-208
Ackman RG (1989) Nutritional composition of fats in seafoods. Prog Food Nutr Sci 13:161-289

Baumert HZ, Simpson J, Sündermann J (eds) (2005) Marine Turbulence. Cambridge University Press, Cambridge

> Bohrer G, Katul GG, Nathan R, Walko RL, Avissar R (2008) Effects of canopy heterogeneity, seed abscission and inertia on wind-driven dispersal kernels of tree seeds. J Ecol 96:569-580

Brigolin D, Davydov A, Pastres R, Petrenko I (2008) Optimization of shellfish production carrying capacity at a farm scale. Appl Math Comput 204:532-540

Chanson H, Trevethan M (2010) Turbulence, turbulent mixing and diffusion in shallow-water estuaries. In: Lang PR, Lombargo FS (eds) Atmospheric turbulence, meteorological modeling and aerodynamics. Nova Science Publishers, New York, NY, p 167-204

Cranford PJ, Li W, Strand Ø, Strohmeier T (2008) Phytoplankton depletion by mussel aquaculture: high resolution mapping, ecosystem modeling and potential indicators of ecological carrying capacity. ICES CM 2008/ H: 12, available at http://ices.dk/products/CMdocs/CM2008/H/H1208.pdf

> Delaux S, Stevens CL, Popinet S (2011) High-resolution computational fluid dynamics modelling of suspended shellfish structures. Environ Fluid Mech 11:405-425

Fan X, Wei H, Yuan Y, Zhao L (2009) Vertical structure of tidal current in a typically coastal raft-culture area. Cont Shelf Res 29:2345-2357

Finnigan J (2000) Turbulence in plant canopies. Annu Rev Fluid Mech 32:519-571

Folkard A (2011) Flow regimes in gaps within stands of flexible vegetation: laboratory flume simulations. Environ Fluid Mech 11:289-306

Fram JP, Stewart HL, Brzezinski MA, Gaylord B, Reed DC, Williams SL, MacIntyre S (2008) Physical pathways and utilization of nitrate supply to the giant kelp, Macrocystis pyrifera. Limnol Oceanogr 53:1589-1603

Gaylord B, Rosman JH, Reed DC, Koseff JR and others (2007) Spatial patterns of flow and their modification within and around a giant kelp forest. Limnol Oceanogr 52:1838-1852

> Ghisalberti M (2009) Obstructed shear flows: similarities across systems and scales. J Fluid Mech 641:51-61

Grant J, Bacher C (2001) A numerical model of flow modification induced by suspended aquaculture in a Chinese bay. Can J Fish Aquat Sci 58:1003-1011

Imberger J, Thompson R, Fandry C (1976) Selective withdrawal from a finite rectangular tank. J Fluid Mech 78: 489-512

> Jackson GA (1984) Internal wave attenuation by coastal kelp stands. J Phys Oceanogr 14:1300-1306

Jackson GA, Winant CD (1983) Effect of a kelp forest on coastal currents. Cont Shelf Res 2:75-80

Jamali M, Zhang X, Nepf HM (2008) Exchange flow between a canopy and open water. J Fluid Mech 611: $237-254$

> Kregting LT, Hurd CL, Stevens CL, Pilditch C (2008) The relative importance of water motion on nitrogen uptake by the subtidal macroalga Adamsiella chauvinii (Rhodophyta) in winter and summer. J Phycol 44:320-330

> Lowe RJ, Koseff JR, Monismith SG, Falter JL (2005) Oscillatory flow through submerged canopies. Part 2. Canopy mass transfer. J Geophys Res 110:C10017 doi:10.1029/ 2004JC002789

> Mcmurtry PA, Riley JJ, Metcalfe RW (1989) Effects of heat 
release on the large-scale structure in turbulent mixing layers. J Fluid Mech 199:297-332

Nikora V, Goring D, Ross A (2002) The structure and dynamics of the thin near-bed layer in a complex marine environment: a case study in Beatrix Bay, New Zealand. Estuar Coast Shelf Sci 54:915-926

O'Riordan CA, Monismith SG, Koseff JR (1995) The effect of bivalve excurrent jet dynamics on mass transfer in a benthic boundary layer. Limnol Oceanogr 40:330-344

Pilditch CA, Grant J, Bryan KR (2001) Seston supply to scallops in suspended culture. Can J Fish Aquat Sci 58: 241-253

Plew DR (2011) Shellfish farm-induced changes to tidal circulation in an embayment, and implications for seston depletion. Aquacult Environ Interact 1:201-214

Plew DR, Stevens CL, Spigel RH, Hartstein ND (2005) Hydrodynamic implications of large offshore mussel farms. IEEE J Ocean Eng 30:95-108

Plew DR, Spigel RH, Stevens CL, Nokes RI, Davidson MJ (2006) Stratified flow interactions with a suspended canopy. Environ Fluid Mech 6:519-539

Plew DR, Enright MP, Nokes RI, Dumas JK (2009) Effect of mussel bio-pumping on the drag on and flow around a mussel crop rope. Aquacult Eng 40:55-61

Rosman JH, Koseff JR, Monismith SG, Grover SG (2007) A field investigation into the effects of a kelp forest (Macrocystis pyrifera) on coastal hydrodynamics and transport. J Geophys Res 112:C02016 doi:10.1029/2005 JC003430

Editorial responsibility: Jonathan Grant,

Halifax, Nova Scotia, Canada
Ruddick B, Anis A, Thompson K (2000) Maximum likelihood spectral fitting: the Batchelor spectrum. J Atmos Ocean Technol 17:1541-1555

Smith A, Nikora V, Ross A, Wake G (2006) A lattice Boltzmann-based model of plankton-flow interaction around a mussel cluster. Ecol Model 192:645-657

Song B, Chen J, Desander PV, Reed DD, Bradshaw GA, Franklin JF (1997) Modeling canopy structure and heterogeneity across scales: from crowns to canopy. For Ecol Manag 96:217-229

Steinbuck JV, Stacey MT, McManus MA, Cheriton OM, Ryan JP (2009) Observations of turbulent mixing in a phytoplankton thin layer: implications for formation, maintenance, and breakdown. Limnol Oceanogr 54: 1353-1368

Stevens CL, Hurd CL, Isachsen PE (2003) Modeling diffusion boundary-layers in subtidal macroalgal canopies: the response to waves and currents. Aquat Sci 65:81-91

Stevens C, Plew D, Hartstein N, Fredriksson D (2008) The physics of open-water shellfish aquaculture. Aquacult Eng 38:145-160

Turner JS (1973) Buoyancy effects in fluids. Cambridge University Press, Cambridge

> van Duren LA, Herman PMJ, Sandee AJJ, Heip CHR (2006) Effects of mussel filtering activity on boundary layer structure. J Sea Res 55:3-14

> Wiles PJ, van Duren LA, Häse C, Larsen J, Simpson JH (2006) Stratification and mixing in the Limfjorden in relation to mussel culture. J Mar Syst 60:129-143

Submitted: May 23, 2011; Accepted: November 13, 2011 Proofs received from author(s): December 15, 2011 